Journal of Educational

and Psychological Sciences

Volume (5), Issue (51): 30 Dec 2021

P: 90 - 109

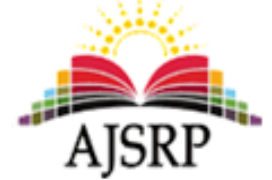

ISSN: 2522- 3399
مجلة العلوم

التربوية والنفسية

المجلد (5)، العدد (51): 30 ديسمبر 2021 م

ص: 90 - 109

\title{
The level of empathy among students of the first three grades in the point of view of their teachers in schools in the schools affiliated to the Marka Brigade in Jordan in the light of some variables
}

\author{
Eman Majed Al- Rbehat \\ Ministry of Education || Jordan
}

\begin{abstract}
This study aimed at investigating the level of empathy among students of the first three grades in the teacher's point of view in the schools affiliated to the Marka Brigade in Jordan in the light of these variables: Gender, Qualifications and the teacher's years of experience. And the sample was formed which was selected randomly between (293) teachers during the second semester of the year (2020/2021), and to achieve the goals of the study a scale was developed to measure the level of empathy, and after verifying the validity and reliability of the scale it was applied to the study sample members, and to find out the level of empathy among students in the first three grades the arithmetic means and standard deviations of the scores of the study sample members were calculated on the study tool, and to examine the differences attributed to the teacher's qualification and experience, the one- way analysis was used. and the study results indicated that the average response of the members of the sample was high, and the study results also indicated that there are no statistically significant differences in the empathy level among the students of the first three grades according to the gender variable of the teacher, and that there are no statistically significant differences at the level of significance $(\alpha \leq 0.05)$ at the total level of empathy among students according to the qualification variable of the teacher, and that there are no statistically significant differences at the level of significance $(\alpha \leq 0.05)$ at the total level of empathy among students of the first three grades according to the experience variable of the teacher. and the researcher concluded a set of recommendations, most notably designing training programs for teachers responsible for the first three grades and activating their role in developing the emotional and social skills of their students, and studying empathy among students at other age stages and from their point of view.
\end{abstract}

Keywords: Empathy, First three grades, Teacher's point of view, Marka Brigade, Jordan.

$$
\begin{aligned}
& \text { مستوى التعاطف لدى طلبة الصفوف الثلاث الأولى من وجهة نظر معلميهم } \\
& \text { في المدارس التابعة لمديرية لواء ماركا في الأردن في ضوء بعض المتغيرات } \\
& \text { إيمان ماجد الربيحات } \\
& \text { وزارة التربية والتعليم || الأردن }
\end{aligned}
$$

\footnotetext{
المستخلص: هدفت هذه الدراسـة إلى تقصي مستوى التعاطف لدى طلبة الصفوف الثلاث الأولى من وجهة نظر معلميهم في المدارس التابعة للواء ماركا / الأردن في ضوء المتغيرات الآتية :الجنس، والمؤهل العلمي، وسنوات الخبرة للمعلم، وقد تكونت عينة الدراسة -والتي تم اختيارها بطريقة عشوائية -من (293) معلمًا ومعلمة، وذلك خلال الفصل الدراسي الثاني من العام (2020/2021) ولتحقيق أهداف الدئي الدراسة تم تطوير مقياس لتقصي مستوى التعاطف، وبعد أن تم التحقق من صدق وثبات المقياس تم تطبيقه على أفراد عينة الدراسـة، ولتقصي
} 
مستوى التعاطف لدى طلبة الصفوف الثلاث الأولى تم حساب المتوسطات الحسابية والانحرافات المعيارية لدرجات أفراد عينة الدراسة على

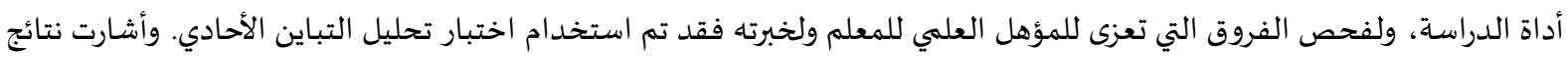

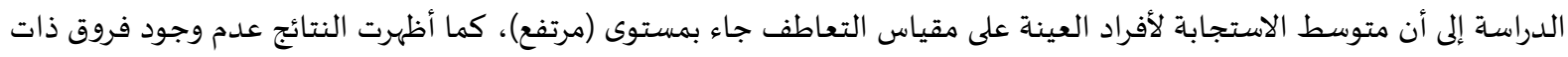

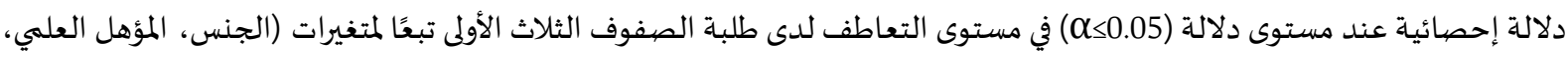

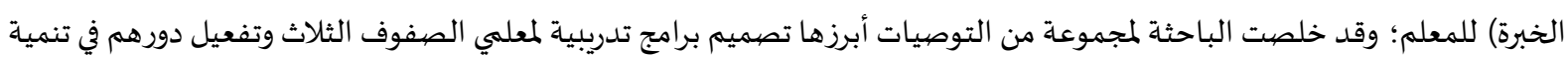

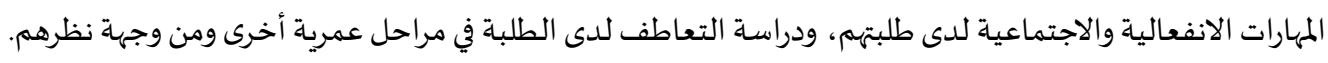

الكلمات المفتاحية :التعاطف، الصفوف الثلاث الأولى، وجهة نظر المعلمين، لواء ماركا، الأردن.

المقدمة.

يعد التعاطف ظاهرة سلوكية انفعالية تقوم على مشاركة الآخرين فيما يشعرون، وله صورة أولية ألا وهي:

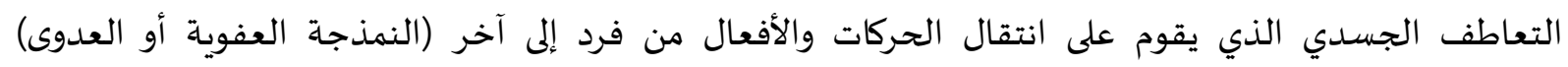

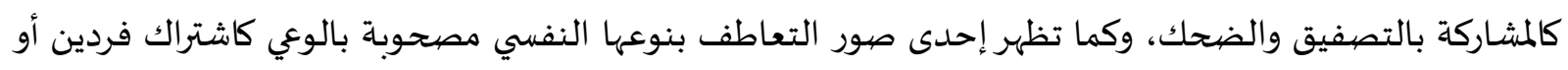

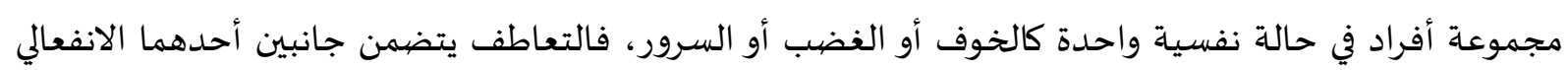
والثاني التفاعلي، ويتمثل الجانب الانفعالي بالشعور بما لحق التهالي الآخرين من حوادث، أما الجانب التفاعلي فهو يتمثل بمعاونتهم وتشجيعهم على تحمل ما داهمهم من متغيرات شاقهـ (Allport, 1960).

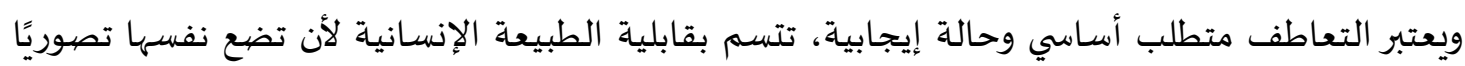

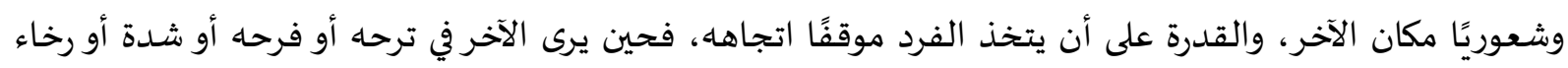

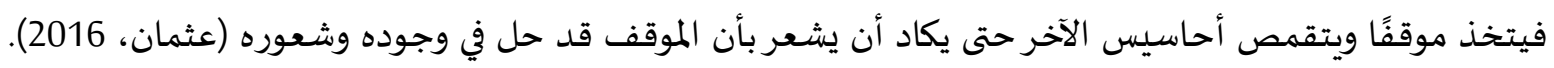
ويرى بوليي أن الطفل عندما يتفاعل مع الآخرين يشكل "نماذج عاملة داخلية (Internal working model)

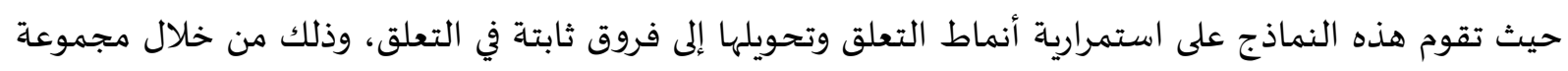

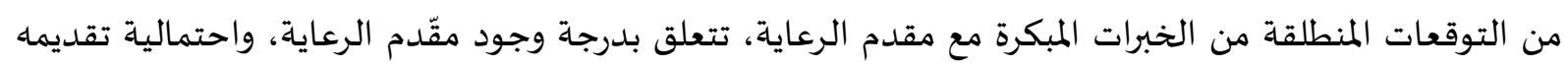

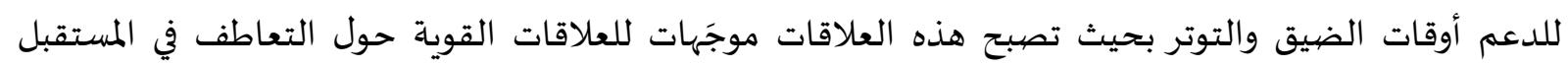
(Bowlby, 1979)

ويعتمد تعلم الطفل التعاطف مع الآخرين إلى درجة كبيرة على ظروف البيئة الاجتماعية، فبعض البيئات

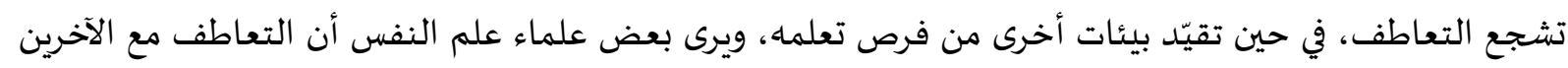

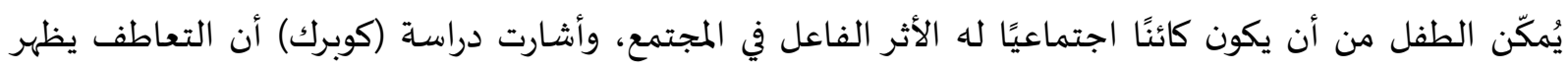

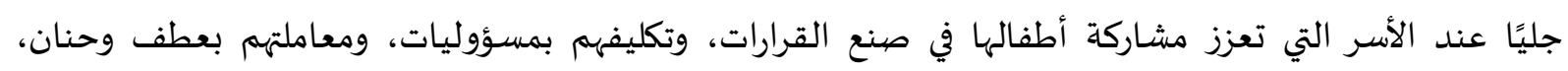
بالإضافة إلى تذكيرهم بعواقب سلوكياتهم وأفعالهم تجاه الآخرين (Thomas, 1979).

مشكلة الدراسة: يعد التعاطف من أهم المفاهيم التي يجب إكسابها للطفل، لما له من علاقة مباشرة ووثيقة بالتربية

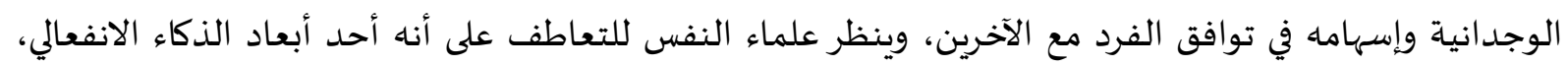

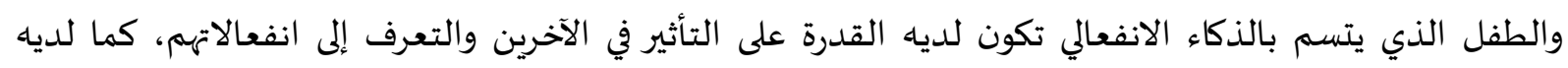

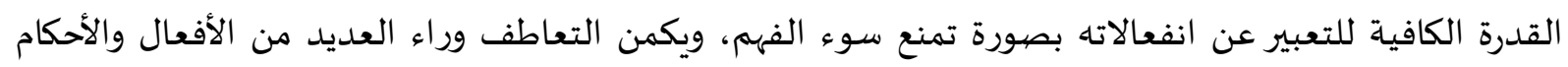

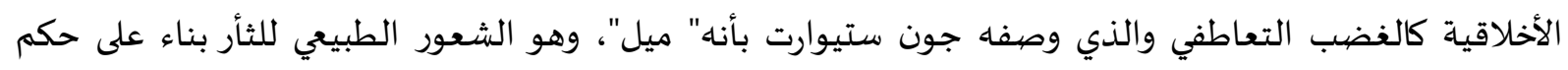

العقل والعطف على أولئك الذين تعرضوا للإيذاء وجرحت مشاعرهم فجرحت مشاعرنا معهم (Reid, 2003). 
وتكمن مشكلة الدراسة الأساسية في ضعف تفعيل وسائل تنمية التعاطف لدى الأطفال في الصفوف الثلاث

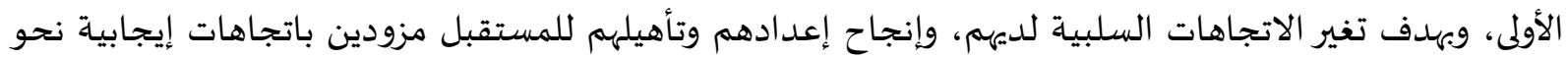

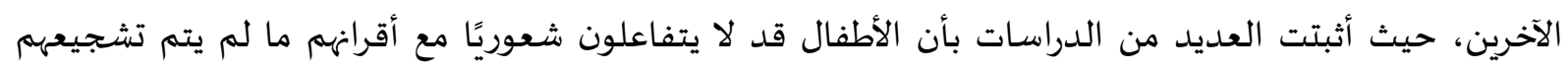

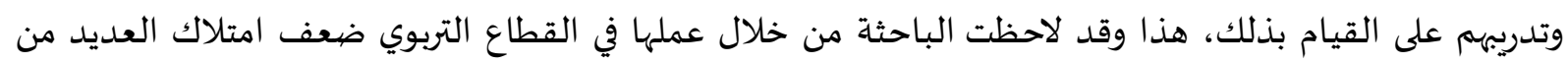

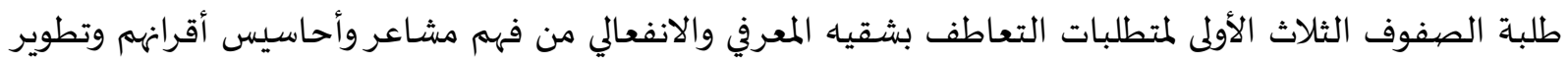

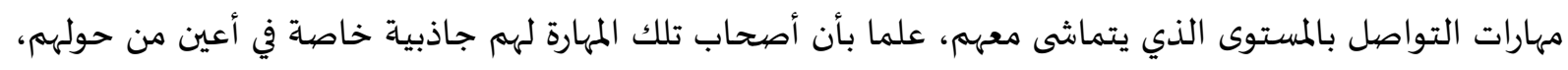
ومن هنا جاء الدافع لدى الباحثة لقياس مستوى التعاطف لدى طلبة الصفوف الثلاث الأولى من وجهة نظهر معلميهم.

وقد ظهرت ضرورة ملحة لمعرفة مستوى التعاطف لدى الطلبة في الصفوف الثلاث الأولى؛ لما له من أثر في

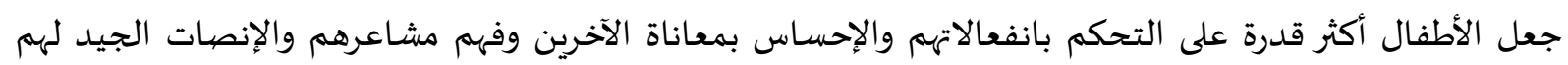

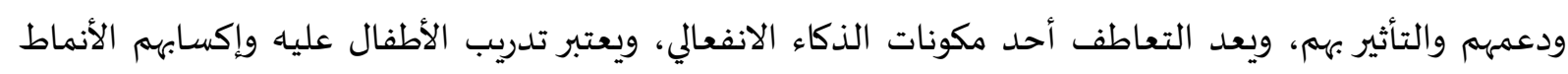

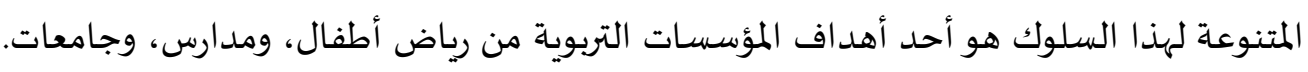

أسئلة الدراسـة: 1- ما مستوى التعاطف لدى طلبة الصفوف الثلاث الأولى من وجهة نظر معلميهم في المدارس التابعة لمديرية لواء ماركا؟ 2- هل توجد فروق ذات دلالة إحصائية عند مستوى دلالة (م> 0.05) في مستوى التعاطف لدى طلبة الصفوف

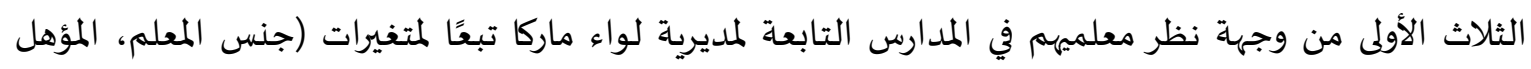

العلمي، الخبره؟

أهداف الدراسة: 1. تقصي مستوى التعاطف لدى طلبة الصفوف الثلاث الأولى من وجهة نظر معلميهم في المدارس الحكومية التابعة لمديرية التربية والتعليم للواء ماركا في الأردن.

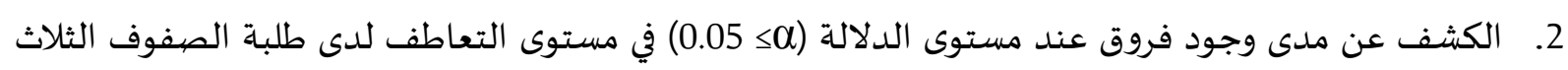

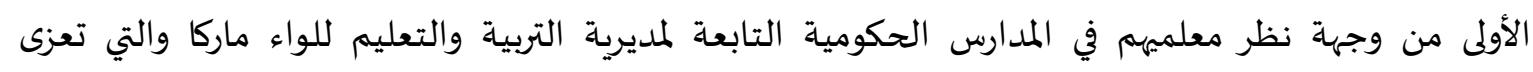
لمتغيرات (الجنس. المؤهل العلمي للمعلم، وخبرته). أهمية البحث: تكمن أهمية الدراسة من الاهتمام البحثي الملحوظ مؤخرًا بالذكاء الانفعالي والذي يعد التعاطف أحد أبعاده

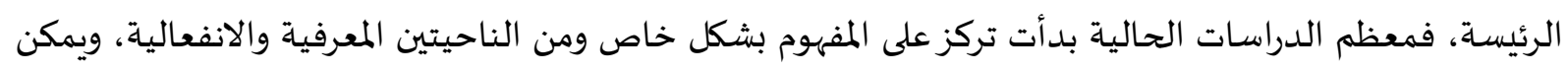

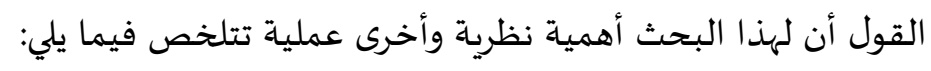

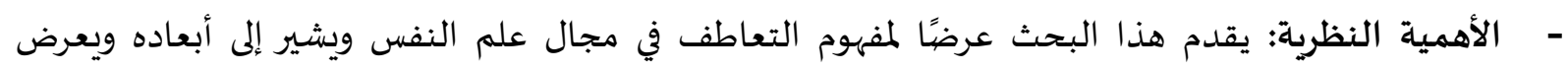

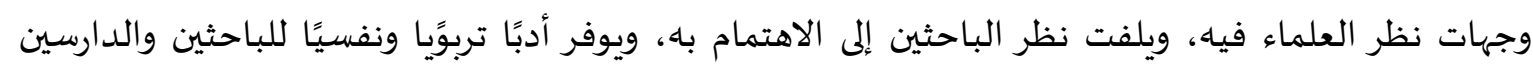

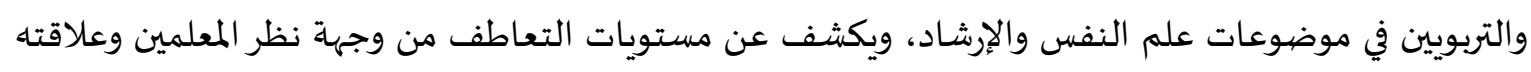

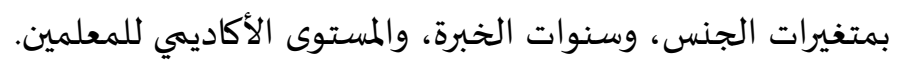


- الأهمية العملية: تزويد الباحثين بمقياس لمستوى التعاطف لدى الطلبة من وجهة نظر معلميهم ذي خصائص

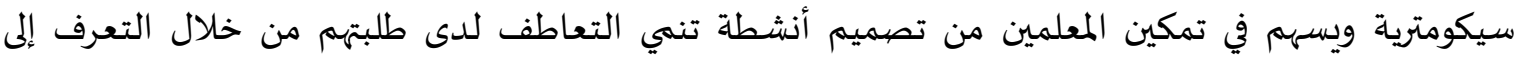

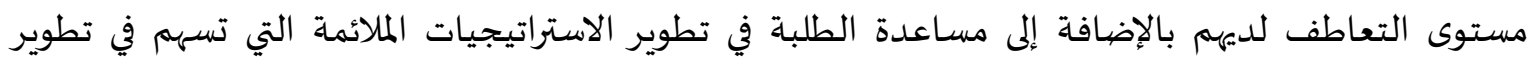

التعاطف لديهم.

حدود الدراسة:

اقتصرت الدراسة الحالية على الحدود الآتية:

هالحدود الموضوعية: التعاطف لدى طلبة الصفوف الثلاث الأولى من وجهة نظر معلميهم.

الحدود البشرية: تكونت عينة الدراسة من (293) معلمًا ومعلمة للصفوف الثونية الثلاث الأولى.

الحدود المكانية: تم تطبيق الدراسة الحالية في المدارس التابعة لمديرية التربية والتعليم للواء ماركا. الحدود الزمانية: تم تطبيق الدراسة الحالية بداية الفصل الثاني من العام الدراسي (2020- 2021).

التعريفات المفاهيمية والإجرائية:

- التعاطف: يعرف بأنه بناء متعدد الأبعاد، يتكون من البعد الوجداني والبعد المعرفي، واللذان يعكسان القدرة

على فهم وتبنيّ وجهة نظر الآخرين بهدف فهم مشاعرهم وانفعالاتهم (Grant, 2010). O ويعرف إجرائيا: بأنه الدرجة التي حصل عليها الطيها الطالب وذلك من خلال استجابة معلماه على فقرات مقياس التعاطف من وجهة نظره والمستخدم في هذه الدراسة والمطوّر من قبل الباحثة.

2- - الإطار النظري والدراسـات السـابقة.

أولاً - الإطار النظري:

التعاطف (Empathy): يعد التّعاطف مفهومًا معقّدًا ومتعدد الأبعاد، حيث يتضمّن أبعادًا عدة ذات جوانب

عاطفيّة، وأخلاقيّة، وإدراكيّة، وسلوكيّة، وقد أشار العديد من الباحثين إلى مكونات التّعاطف كل من منطلقه النظري، حيث قِدم جولمان (Goleman) نموذجًا في الذكاء الانفعالي وتضمن خمسة أبعاد مصنفة ضمن مكونين أساسيين هما: المكونات الشخصية، وتضم ثلاثة أبعاد هي: (الوعي الذاتي الانفعالي، وتنظيم وإدارة الانفعالات، والدافعية وحفز الذات)، في حين تضمن المكون الثاني بعدين هما: المهارات الاجتماعية والتعاطف، ويقصيد بالتعاطف إدراك مشاعر الآخرين واهتماماتهم وحاجاتهم (Goleman, 1998) .

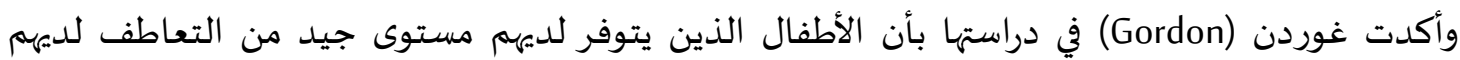
تفاعلات اجتماعية جيدة مع الآخرين، ويتمتعون بصحة نفسية إيجابية، ولديهم قدرة على تكوين علاقات مع أقرانهم

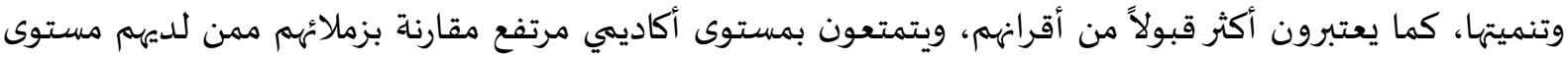

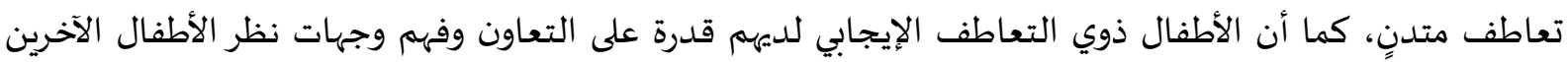

.(Gordon, 2013)

وأشار جولمان (Goleman) إلى أن المهارات العاطفية قابلة للتعلم، وعلى الرغم من الاختلاف بين الأطفال،

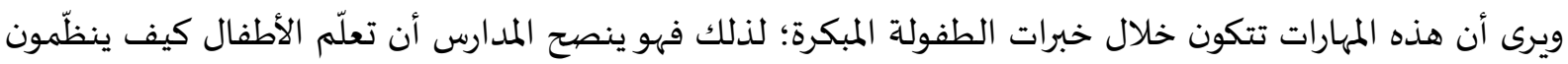
مشاعرهم ويتحكمون فيها، ويوجهونها الوجهة الصحيحة في المواقف المختلفة، وأن على المعلمين أن يكونوا نماذجًا

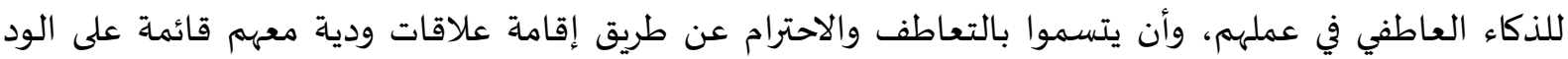


والاحترام (جولمان، 2000). وترى الباحثة أن تنمية التعاطف لدى الطلبة أصبح ضرورة ملحة في وقتنا الحاضر،

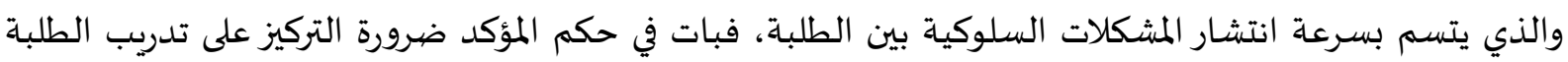

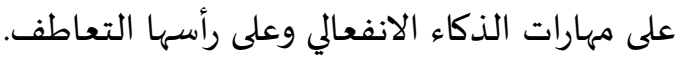
وترى الباحثة بأن التعاطف سمة إنسانية فطرية تولد مع الفرد، والفرق بين الأفراد في درجة امتلاكها وليس في نوعها، وعليه يمكن تنميتها وتدريب الفرد عليها في عمر مبكر للوصول إلى المستوى المطلوب باستخدام الوسائل بهائ المتنوعة كالنمذجة، والدراما، ولعب الأدوار.

مفهوم التعاطف:

يعد (ليبس) أول من استخدم مفهوم التعاطف عام (1897)، وهناك العديد من التعريفات الحالية للتعاطف تعتمد في الغالب على تعريف روجرز (1975) حيث يصف التعاطف على أنه إدراك الفرد للحالة الداخلية للشخص بدقة، ويشمل مكونات وجدانية ومعرفية وتواصلية (Ancel, 2006). وقد طرح الأدب التربوي تعريفات عدة تختلف باختلاف المنطلقات النظرية ومنها: - عرفه ديبيو (Dpew) بأنه المشاركة الوجدانية لما يشعر به الآخرين من انفعالات مختلفة مع تصورنا لكيفية تفكير الآخرين وما يشعرون باه (Depew, 2005). - فيما عرفه أيزنك (Eysenck) على أنه القدرة على مشاركة الشخص الآخر انفعالاته، وفهم وجهة نظره .(Eysenck, 2003) - وعرفه دايموند (Dymond) بأنه "الانتقال أو التحويل التخيلي لشخص ما إلى تفكير ومشاعر وسلوك شخص آخر، ومن ثم تصور العالم كما يراه الشخص الآخر" (Dymond, 1949). - وأشار كازدن (Kazdin) إلى أن التعاطف استجابة انفعالية عاطفية ترتكز على فهم الحالة الانفعالية للآخر،

ويتضمن مشاعر الحب والاهتمام بالآخر مع تبادل المشاعر الإيجابية (Kazdin, 2000). ويرى هوفمان (Hoffman) بأن التعاطف استجابة تعبيرية مؤثرة تنوب عن الآخرين، وتعتمد إلى درجة كبية كبيرة على قدرة الفرد على أن يحل إدراكيًا مكان الشخص الشعان الخدر (Hoffman, 1988). وترى الباحثة أن التعاطف يتمثل بقدرة الفرد على إدراك ما يشعر ويفكر به الآخرون ومشاركتهم عواطفهم الإنه من خلال الاتصال المعرفي والوجداني. النظريات المفسّرة للتعاطف: - أولًا: نظرية هوفمان (Hoffman theory) يرى هوفمان بأن التعاطف عبارة عن التفاعل القائم بين الحس المعرفي بالآخرين والمشاعر التعاطفية، وهذا

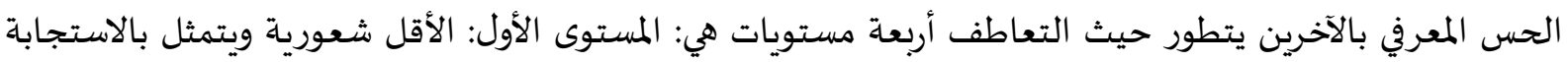

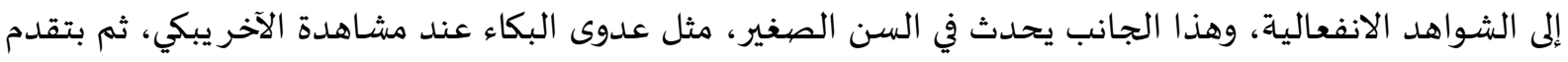

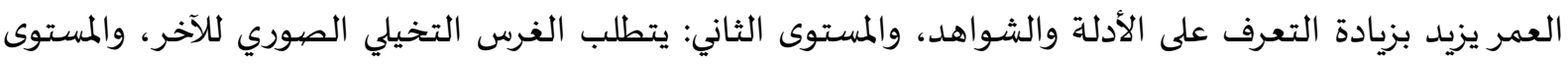

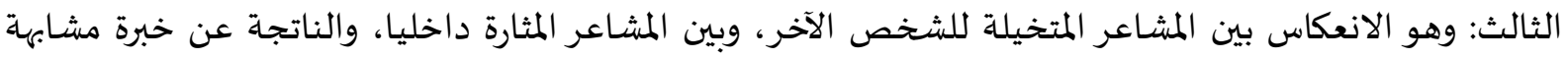

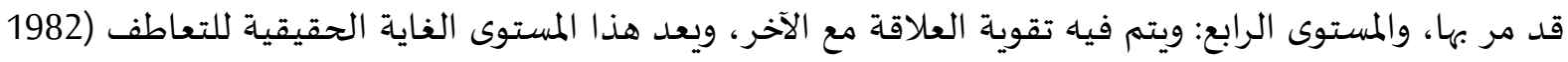
.(Hoffman, 
- ثانيًا: نظرية ثيورد لبس (Theodor Lips theory) ويرى (لبس) بأن التعاطف ناتج عن استجابة تقليدية، فعندما يلاحظ فرد وقوع آخر تحت تأثير شعور ما،

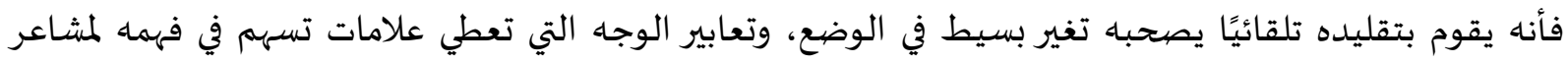

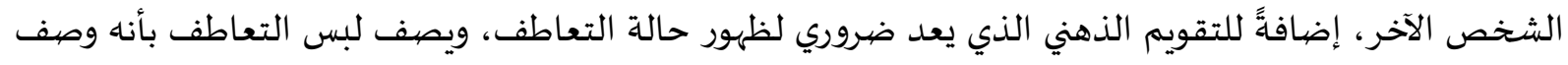

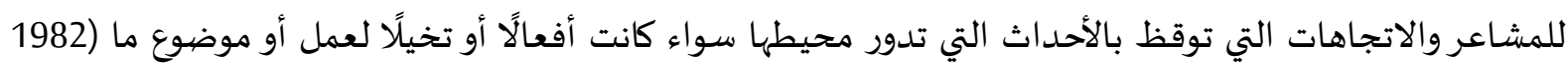

.(Hoffman,

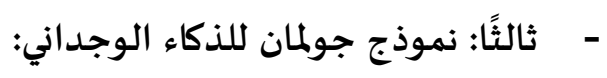

ويرى جولمان بأن التعاطف هو أحد أبعاد نموذجه الخمسة والمتمثلة بالوعي الذاتي، وإدارة الوجدان، وإنان

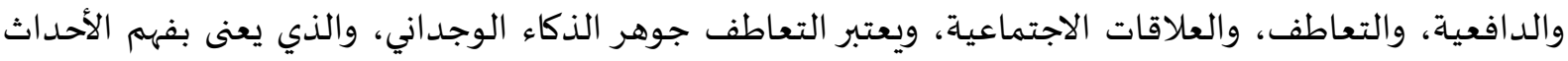

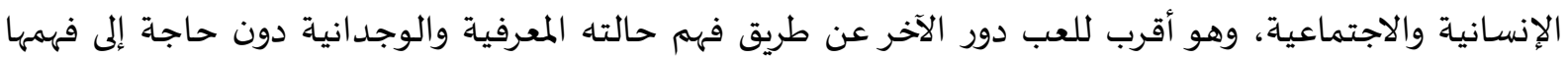

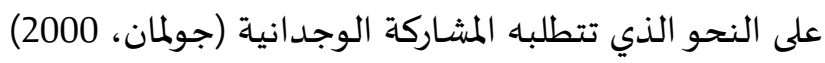

- رابعًا: نظرية التحليل النفسي (Psychology Analysis Theory) يرى فرويد بأن التعاطف نشاط لا شعوري يقوم على الغريزة، ومرتبط بخبرات الطفولة، إذ أن للفرد حاجة النها

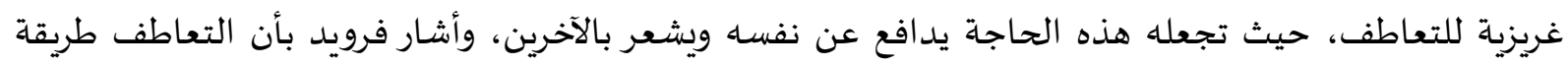

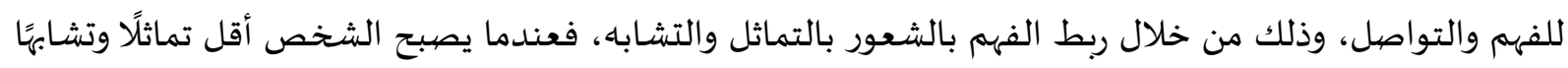

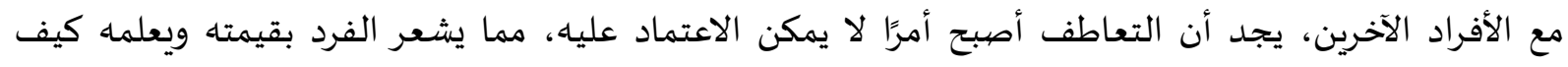

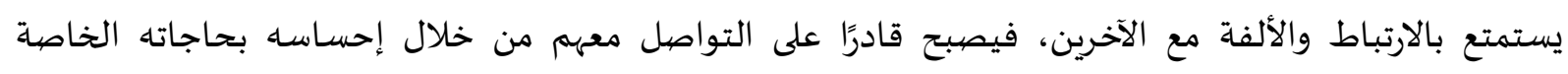
وحاجات الآخرين (Scotland, 1969).

المراحل التطورية للتعاطف عند الأطفال: يولد الناس ويولد معهم الشعور بالتعاطف فطريًّا ويتطور بتقدم العمر، حيث يظهر عبر مراحل تطورية وهي كالآتي (Hoffman, 1988): - المرحلة الأولى: وتسمى مرحلة التعاطف العام، حيث تظهر لدى الطفل حديث الولادة، وتكون الاستجابة

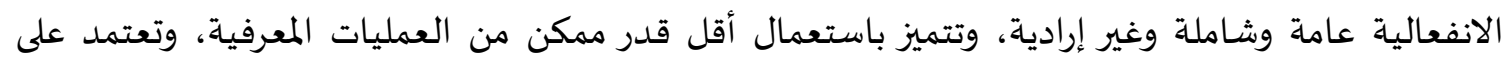

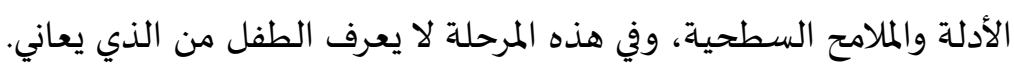

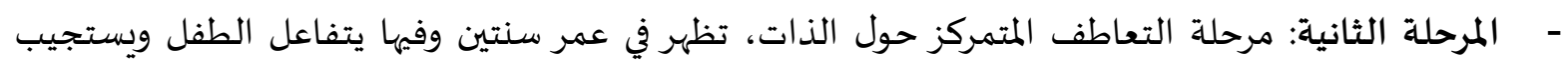

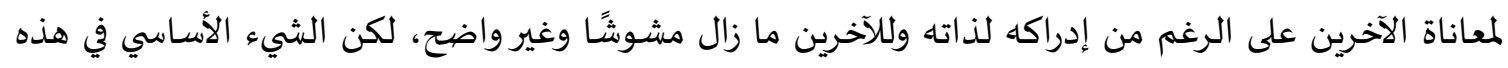
المرحلة هو أن الآخر هو الذي يعاني، ولكنها غير قادر على استيعاب وفههم السبب الحقيقي للمعاناة، أن التطور

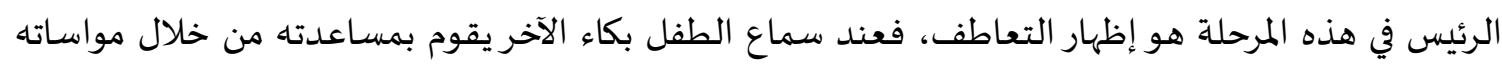
كأن يعرض عليه لعبته الخاصية والمفضلة لدياه.

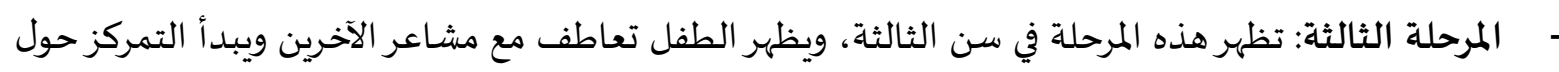

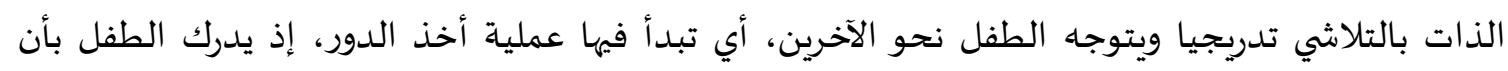
للآخرين حاجات داخلية ووجهات نظر تختلف عن حاجاته ووجهة نظره، ويستطيع الطفل في هذه المرحلة ولأول مرة أن يتخيل نفساه مكان الآخرين. 
- المرحلة الرابعة: تظهر هذه المرحلة عندما يصل الطفل إلى مرحلة الطفولة المتوسطة، ويكون الطفل فيها واعيًا بأن الأشخاص يشعرون بالفرح والحزن ليس في المواقف الحالية فقط لكن في سياق خبرات المرات الحياة الممتدة،

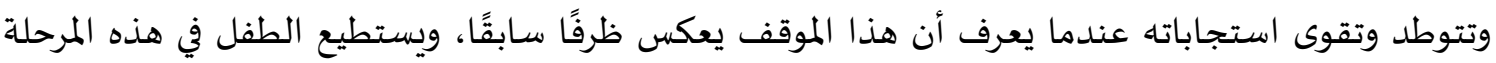

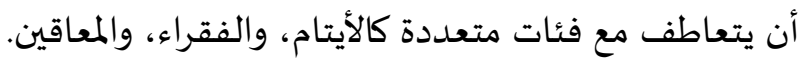

العوامل المؤثرة في تطور التعاطف:

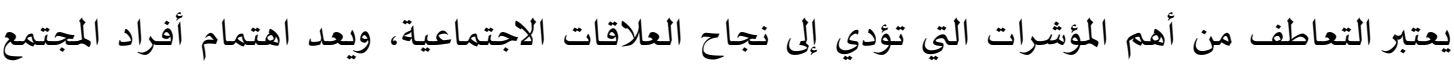

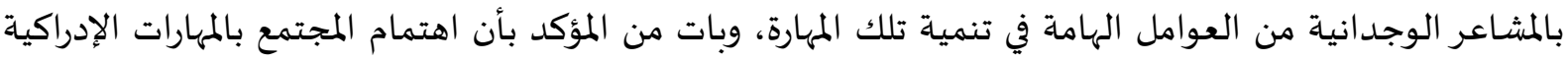

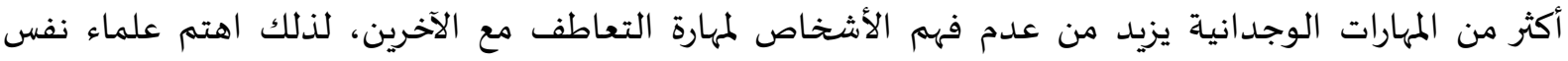
الشخصية بالتعاطف، حيث يشير جوردون ألبورت إلى أن التعاطف له دور كبير في حياة الأشخاص (Allport, 1960).

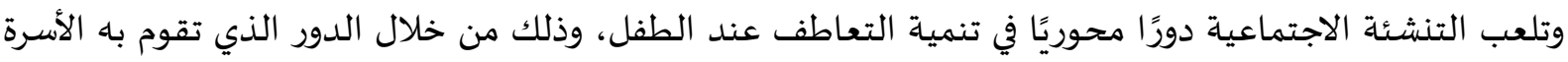

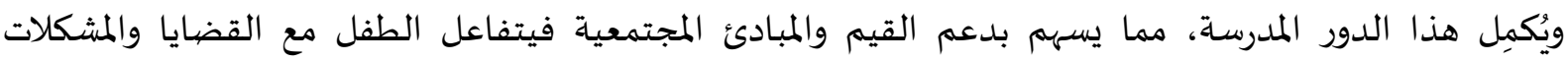

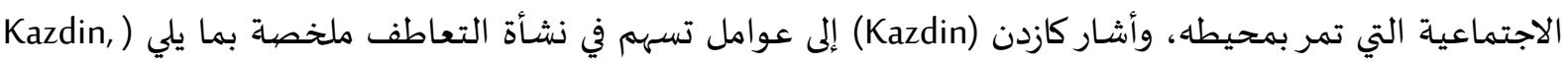

1- العوامل الاجتماعية والثقافية: وتتمثل بالوضع العام للأسرة في المجتمع ومدى فاعلية أدوارها فياه، لأن هذه

الأدوار تحدد نوعية الأصدقاء للطفل.

2- العوامل النفسية: يأتي في مقدمة هذه العوامل رغبة الطفل الجامحة لإظهار نفسـه بهدف الحصهول على قدر

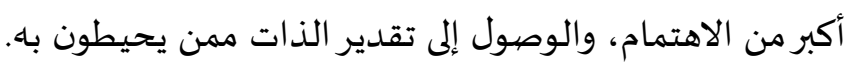

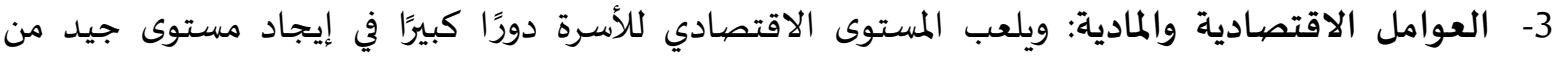

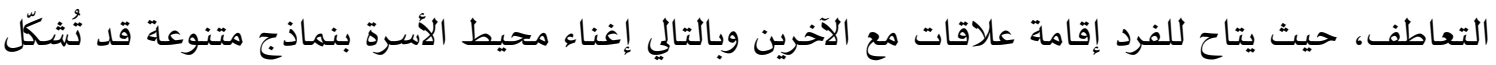

نماذج حياه في التعاطف. تئف

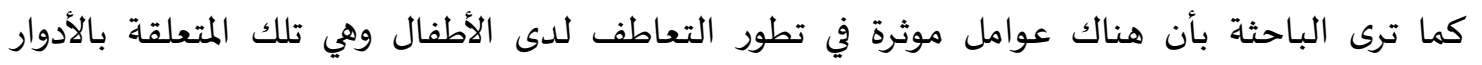

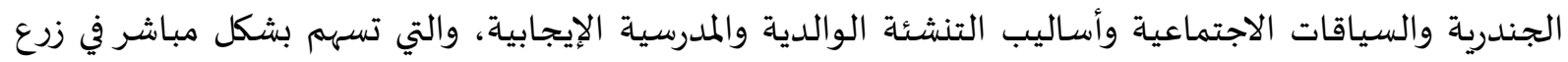

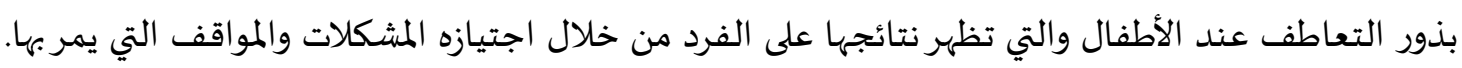

متطلبات التعاطف:

أشار جولمان بأن للتعاطف مجموعة من المتطلبات والتي أوردها (النهان، 2004) وهي:

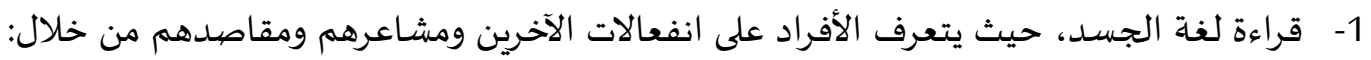

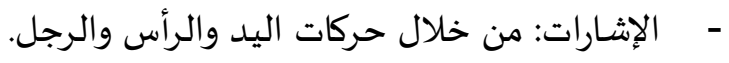

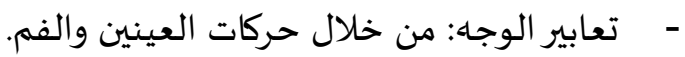

- وضعية الجسم: من خلال مشية الفرد وجلسته، ويرى أن هذه المهارات تتكون خلال خبرات الطفولة المبكرة.

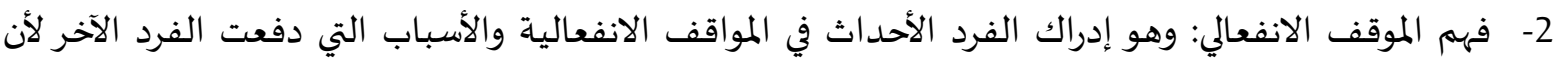
يعبر عن انفعال ما، كالضحك، البكاء والغضب، وكيف يمكن أن يشعر ويعتمد وعي الفرد بانفعالات الآخرين على أساس وعياء بانفعالاته. - عان. 
أبعاد التعاطف:

أورد جولمان التعاطف كبعد رئيس ضمن الأبعاد الخمسة للذكاء العاطفي، وتضمن التعاطف عدة أبعاد

وهي) (Goleman, 1998)

1. ههم الآخرين: ويتمثل هذا المكون بفهم مشاعر الآخرين وتقبل آرائهم، والحرص على الاهتمام بما يشغلهم. 2. تطوير الآخرين: بإدراك حاجات الآخرين للتطور ودعم قدراتهم، ويظهر ذلك من خلال الاعتراف بنقاط القوة

لدى الآخرين، وتعزيزهم على إنجازاتهم.

3. التنوع المؤثر: بتعزيز الفرص بين الأفراد، وتبدو هذه الكفئماية من خلال احترام الأفراد مهما كانت خلفياتهه،

بالإضافة إلى تفهم وجهات النظر المختلفة.

4. الوعي السياسي: ويظهر هذا المكون من خلال قدرة الفرد على معرفة الميول الانفعالية للجماعة وارتباطها

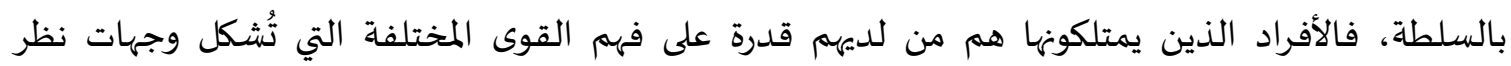
الأفراد، وكما يدركون بدقة العلاقات بين القوى الأسـاسية.

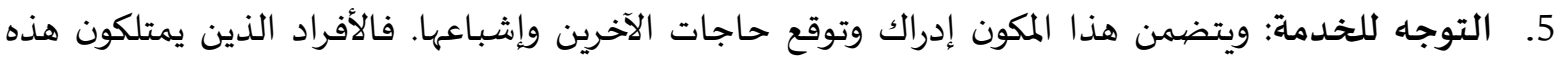

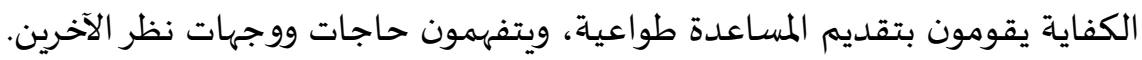
في حين أشار جوناثان بأن التعاطف يتمثل بثلاثة أبعاد هي (Jonathan, 2005): 1. التعاطف الوجداني: ويتمثل بردود فعل الشخص تجان انتهاه مشكلات الأفراد الآخرين.

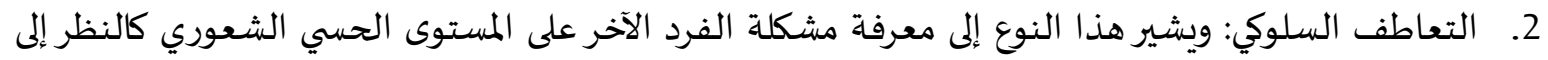
الانفعالات الظاهرة على الشخص، واستجابة الشخص لهدير لهذه الانفعالات. 3. التعاطف المعرفي: ويقصد باه التعرف وإدراك وفهم المشكلات التي يمر بها الفرد.

خصائص الأشخاص المتعاطفين: أشارت العديد من الدراسات إلى أن الفرد المتعاطف يتسم بخصائص المتعان عدة والتي تتمثل بما أورده كل من (Turner, 2014) و (Vaknin, 2009) في دراسة لكل منهما، وهي:

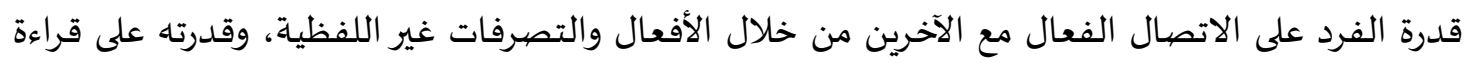

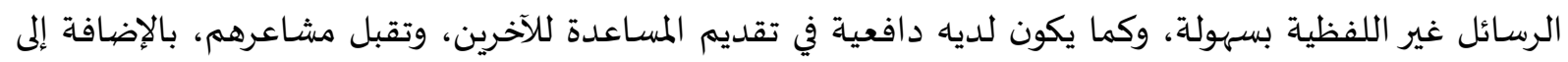

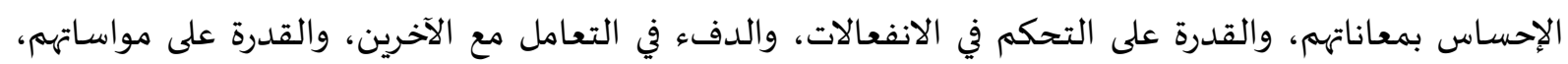
والإنصات الجيد لهم، وإدراك وفهم مشاعرهم.

التطبيقات التربوية للتعاطف: يرى جولمان (Goleman) بأن المهارات العاطفية قابلة للتعلم، وعلى الرغم من الاختلاف بين الأطفال، ويرى أن هذه المهارات تتكون خلال خبرات الطفولة المبكرة لذلك فهو ينصح المدارس أن تعلم الأطفال كيف ينظمون

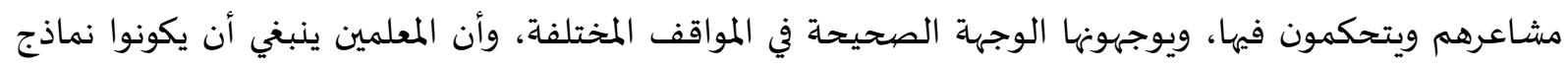

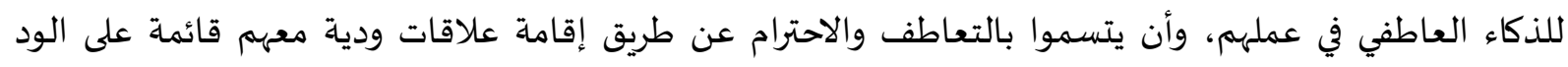
والاحترام (جولمان، 2000). وفيما يلي مجموعة من التطبيقات والأنشطة التي تعزز التعاطف لدى الأطفال كما أوردتها (حسونة، 
أولاً: أنشطة خاصة بالوالدين.

- الزيارات القصدية: وتتم باصطحاب الأطفال في زيارات إلى دور رعاية كبار السن أو دور الأيتام، أو زيارة الأطفال

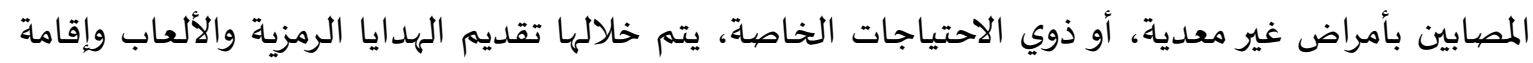

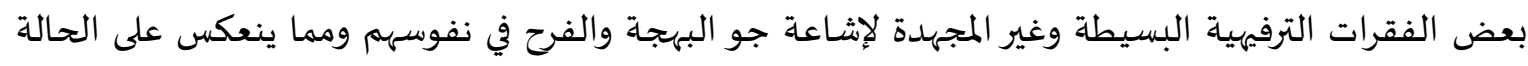

النفسية لهم.

نمذجة الآباء للتعاطف: وذلك من خلال إظهار الآباء لسلوك التعاطف مع الأطفال ومع من حولهم بمواقف

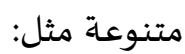

أ- رعاية الصغاروالتعاطف معهم عند بكائهم ومداعبتهم ليتبدل حزنهم إلى فرح، وترك المجال للطفل للمشاركة في

رعاية الصغيروتحت إشراف الأم أو من قبل الأفراد الراشدين.

ب- تخصيص مكان في المنزل لتربية النباتات ودعوة وتدريب الطفل على العناية بها بصورة مستمرة وبيان

احتياجاتها.

ج- التعاطف مع الحيوانات والطيور والأسماك التي قد توجد في المنزل وإشراك الأطفال في رعايتها وتغذيتها، على أن تكون تحت أشراف الوالدين.

- - التدريب على التخيل لإدراك وجهات نظر الآخرين من خلال وضع الذات موضع الآخر.

- - عرض الأفلام التي تعرض قصصيًا للتعاطف مع الفئات المختلفة. - استخدام الدراما والتمثيل الجماعي في تمثيل سكيتشات مسرحية تتضمن موضيوعات، مثل: زيارة مريض، والرفق بالحيوان، ومسـاعدة الزملاء.

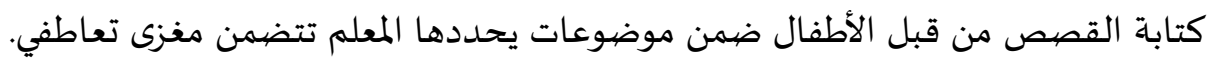

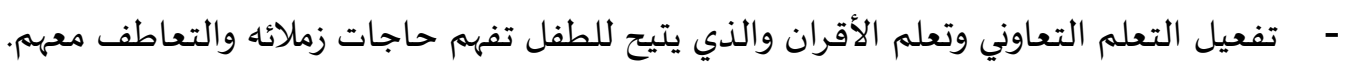

- الموسيقا والأناشيد المتضمنة رسائل تحث الطفل على التعاطف وتأدية حركات دالة دالة عليه.

ثانيًا: أنشطة خاصية بالمعلمة:

- - تقديم القصص والحكايات عبر مسرح الدمى، متضمنة نماذج تحاكي التعاطف. - لعب الدور ضمن مواقف اجتماعية وتمثيل المشاعر وتخيلها بهدف تنمية التعاطف الوجداني والمعرفي. - عرض الأفلام التي تعرض قصصيًا للتعاطف مع الفئات المختلفة. - استخدام الدراما والتمثيل الجماعي في تمثيل سكيتشات مسرحية تتضمن موضوعات مثل: زيارة مريض الرفق

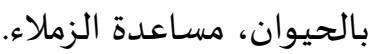
-

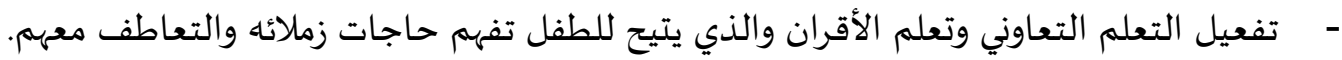
- الموسيقا والأناشيد المتضمنة رسائل تحث الطفل على التعاطف وتأدية حركات دالة على ذلك.

ثانياً- الدراسات السابقة:

يعد التعاطف أحد الموضوعات الهامة الانفعالية التي بدأ البحث فهها مؤخرا في ميدان علم النفس ويلاحظ

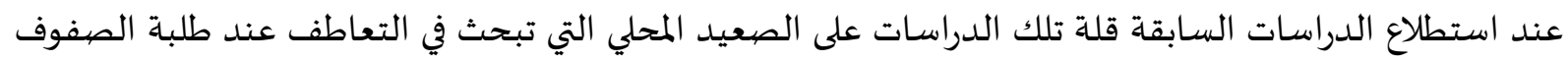
الثلاث الأولى، وفيما يلي مجموعة من الدراسات التي تناولت هذا الموضيوع: 
- أجرى أفشي وساك (Avcı \& Sak, 2021) دراسة هدفت إلى استقصاء العلاقة بين التعاطف والعدوانية لدى طلبة

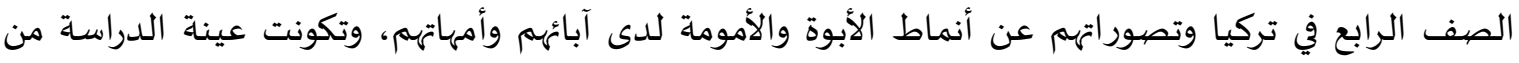

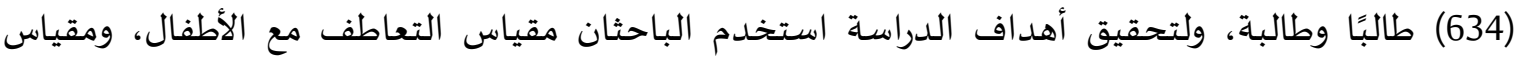

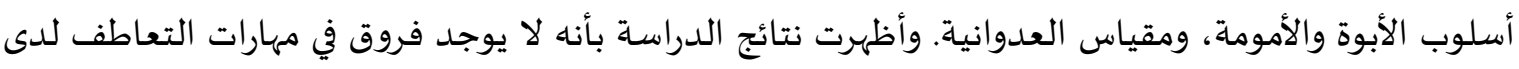

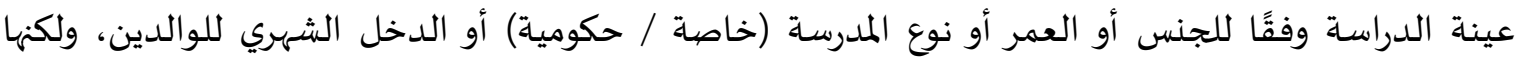

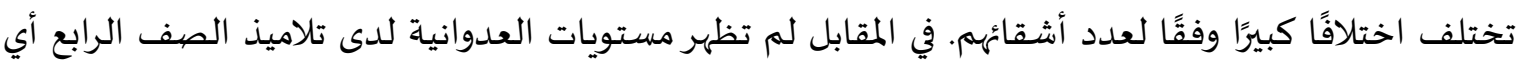

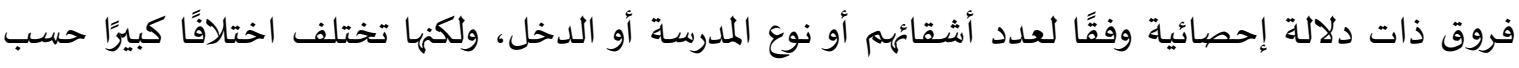

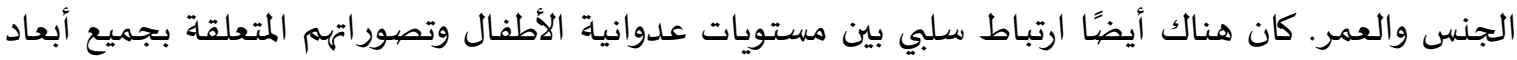
مقياس أسلوب الأبوة والأمومة، كما لم تكشف النتائج عن وجود علاقة ذات التهات دلالة إحصائية بين مهارات التعاطف لدى الأطفال الذين شملهم الاستطلاع ومستويات العدمات العدوانية. وفي دراسة أجراها كل من فريدرك وجينكينز وراي (Fredrick, Jenkins \& Ray, 2020) بهدف التعرف على العلاقة بين التعاطف ببعديه المعرفي والوجداني والخطوات الخاصة للتدخل في حالة التنمر (ملاحظة أحداث التنمر تقبل المسؤولية عن التدخل - معرفة كيفية التدخل - والتصرف) وتكونت عينة الدراسة من (336) طالبًا

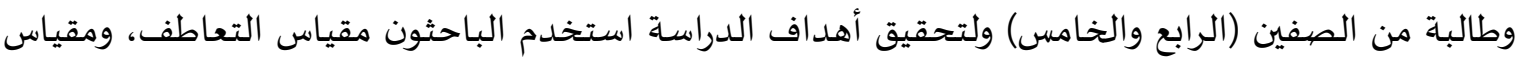

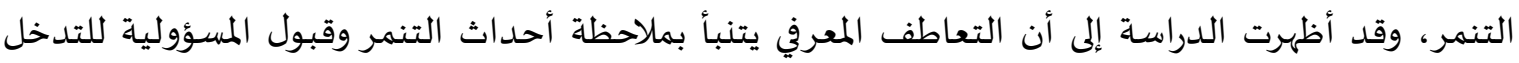

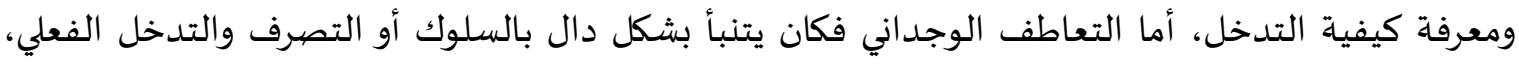
كما أشارت نتائج الدراسة إلى أن التعاطف المعرفي يرتبط بشكل إيجابي ودال إحصائيا بتفسير التنمر كحدث

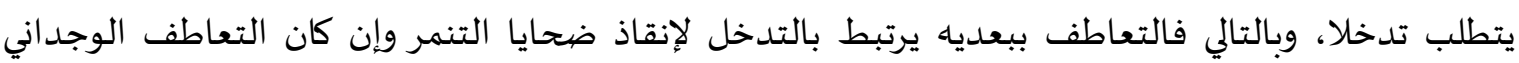
يرتبط أكثر بالسلوك الفعلي. وأجرت بشير عبد الأحد (2020) دراسة في العراق هدفت التعرف على التعاطف الوجداني وعلاقته بالذكاء

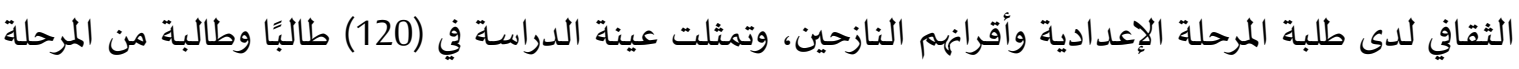

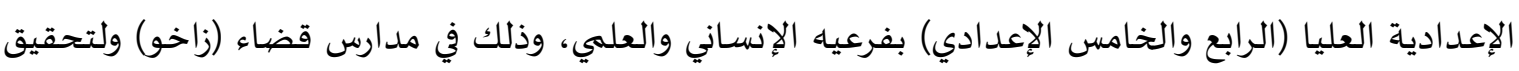

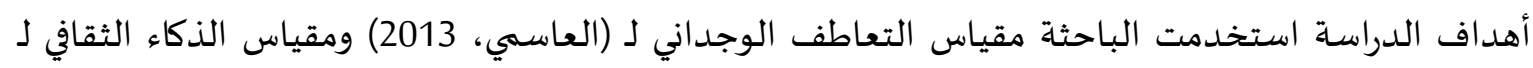

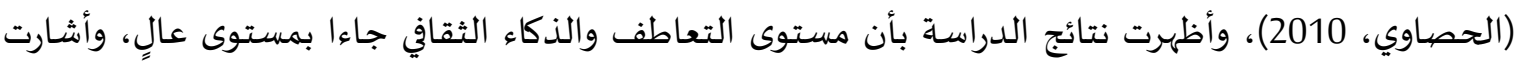

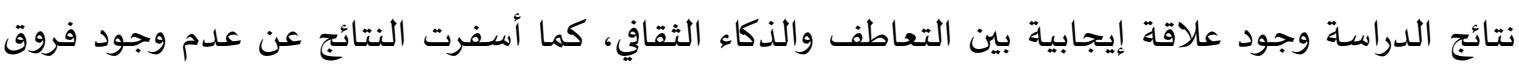

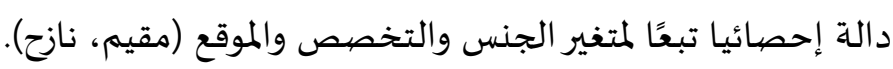

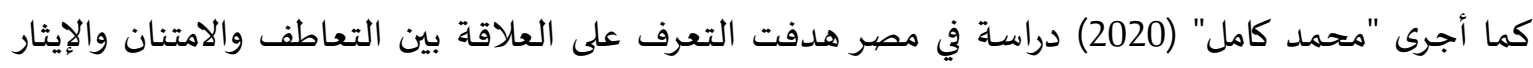

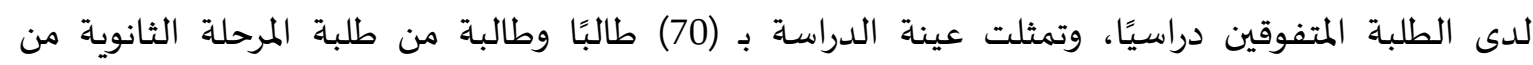

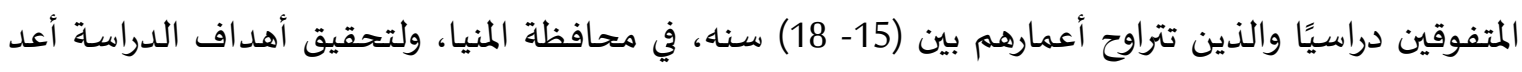

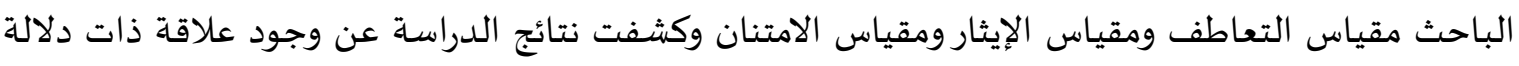

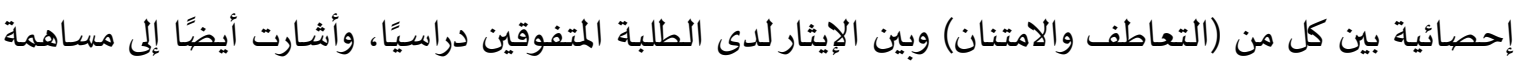

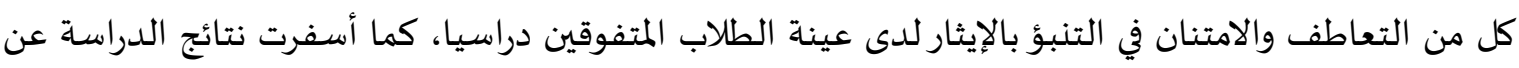
عدم وجود فروق في التعاطف والامتنان والإيثار تبعًا لمتنير الجنس.

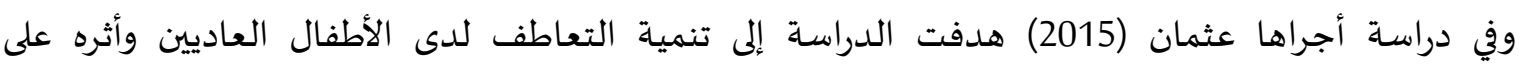

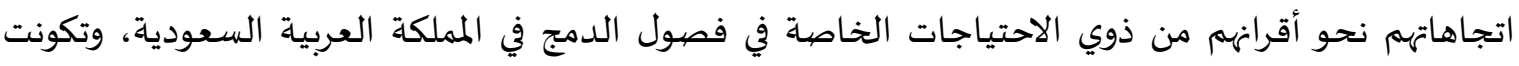


عينة الدراسة من عينة استطلاعية قوامها (150) طالبًا وطالبة من المرحلة الابتدائية عليا. وعينة تجريبية مكونة من (50) طالبًا وطالبة ممن حصلوا على درجات سلبية على مقياس الاتجاهات نحو ذوي الاحتياجات الخاصية،

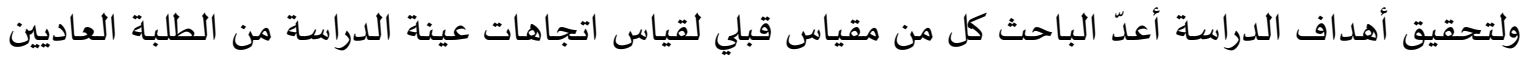
نحو زملاههم من ذوي الاحتياجات الخاصة، وبطاقة ملاحظة استطلاع آراء المعلمين والمرشدين وتقييمهم لطلبتهم

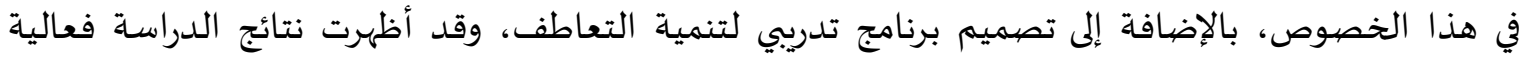
البرنامج التدريبي لتنمية التعاطف وتعديل الاتجاهات السلبية للطلبة العاديين نحو زملاههم من ذوي التهائه الاحتياجات

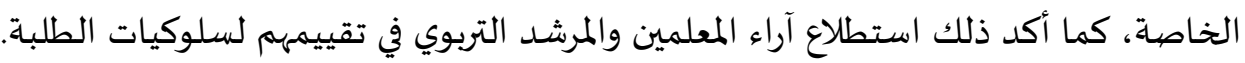
- وأجرت عسكر (2001) دراسة في العراق هدفت التعرف على التعاطف لدى طلبة الجامعة وعلاقته بالذكاء

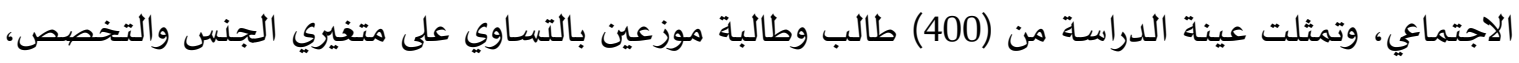
ولتحقيق أهداف الدراسة استخدمت الباحثة مقياس التعاطف المترجم من مقياس (مهربيان وابتستن) بالإضافة

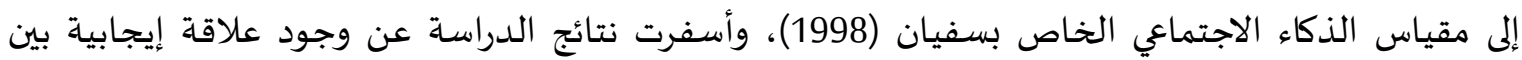
التعاطف والذكاء الاجتماعي، وعدم وجود فروق في التعاطف تبعًا لمتغيري الجنس والتخصص، بلتصاء بينما أشارت

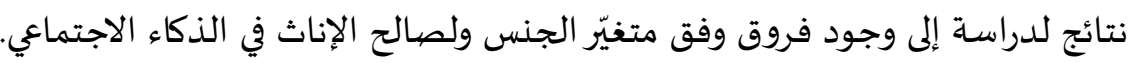

تعليق على الدراسـات السابقة: في ضوء الدراسات السابقة التي تم استعراضها يمكن الوصول إلى أن أهداف هذه الدراسات تنوعت ويمكن

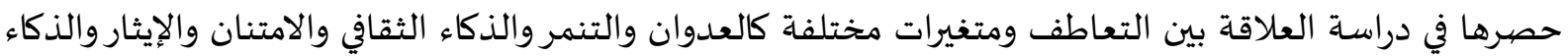
الاجتماعي، وشملت الدراسات مجموعة من المتغيرات الفرعية الخاصة بالطلبة كالجنس، والعمر، ونوع المدرسة

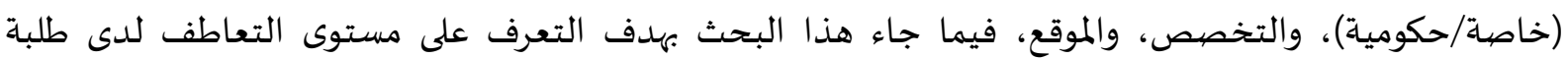

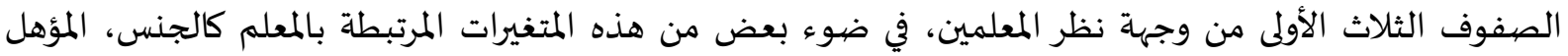

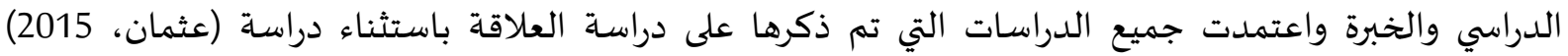

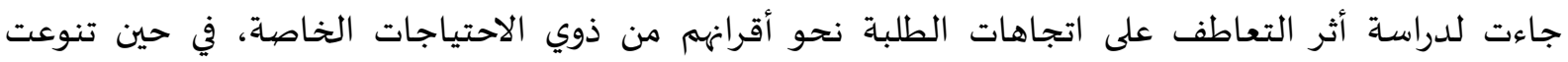

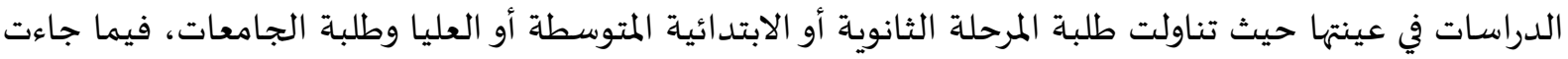
هذه الدراسة لتعتمد في عينتها على طلبة الصفوف الثلاث الأولى، وهم يمثلون ان المرحلة الأساسية الدنيا الديا كعينة

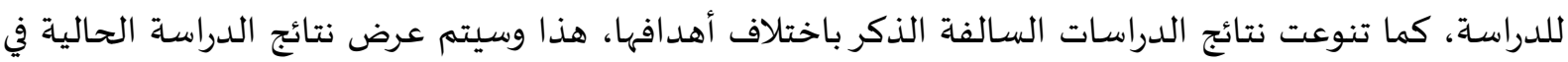
البند المخصص لذلك.

3- منهجية الدراسـة وإجراءاتها.

منهج الدراسة: استخدمت الدراسة الحالية المنهج الوصفي، حيث تم تقصي مستوى التعاطف لدى طلبة الصفوف الثلاث

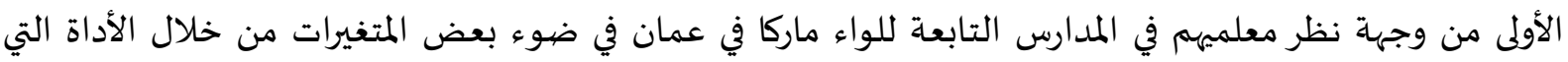
أعدتها الباحثة بعد استخراج خصائصهيا السيكومترية. 
مجتمع الدراسة:

تكون مجتمع الدراسة من جميع معلمي الصفوف الثلاث الأولى في مديرية تربية لواء ماركا والبالغ عددهم

(833) معلمًا ومعلمة، حيث تم اعتماد هذه البيانات من قسم التخطيط التابع لمديرية لواء ماركا.

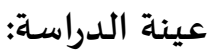

بلغت عينة الدراسة (293) معلمًا ومعلمة تم اختيارهم من خلال العينة العشوائية، لتشكل العينة ما نسبته (35\%) من مجتمع الدراسة، والجدول (1) يوضح توزيع أفراد عينة الدراساة تبعًا لمتغيراتها: جدول (1): توزيع عينة الدراسـة تبعًا لمتغيراتها:

\begin{tabular}{|c|c|c|c|c|}
\hline النسبة & العدد & الجنس & المتغير & 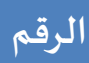 \\
\hline 7.5 & 22 & ذكر & \multirow{2}{*}{ الجنس } & \multirow{2}{*}{1} \\
\hline 92.5 & 271 & أنثى & & \\
\hline 5.8 & 17 & دبلوم متوسط & \multirow{4}{*}{ المؤهل العلمي } & \multirow{4}{*}{2} \\
\hline 79.5 & 233 & بكالوريوس & & \\
\hline 8.5 & 25 & دبلوم عال & & \\
\hline 6.1 & 18 & ماجستير فأعلى & & \\
\hline 22.9 & 67 & 1 - 5 سنوات & \multirow{4}{*}{ الخبرة } & \multirow{4}{*}{3} \\
\hline 25.3 & 74 & 6 - 10 سنوات & & \\
\hline 29.4 & 86 & 11 - 15 سنة & & \\
\hline 22.5 & 66 & أكثر من 15 سـنة & & \\
\hline 100.0 & 293 & \multicolumn{2}{|c|}{ المجموع } & 4 \\
\hline
\end{tabular}

أداة الدراسة: تقصي مستوى التعاطف لدى طلبة الصفوف الثلاث الأولى من وجهة نظر معلميهم:

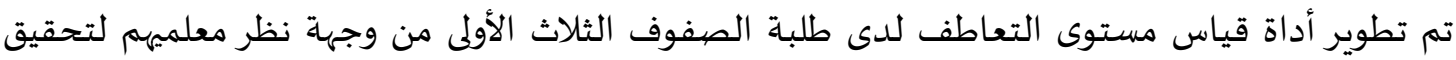

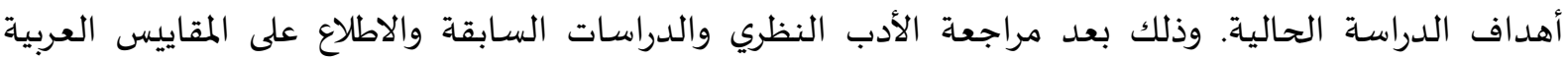

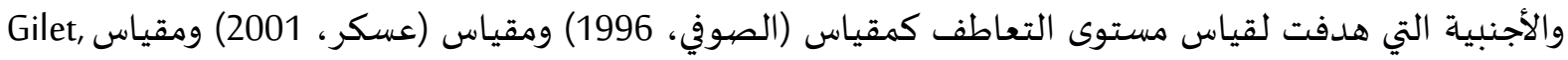
(Mella, Studer Gruhn, \& Labouvie- Vief, 2013) التدريجي الخماسي: (أوافق بشدة، أوافق، محايد، لا أوافق، لا أوافق بشدة).

صبدق أداة الدراسـة: وللتحقق من صددق الأداة تم استخدام طريقة صدق المحتوى وذلك بعرض أداة الدراسـة على عدة محكمين

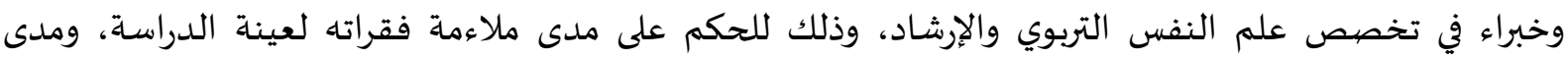

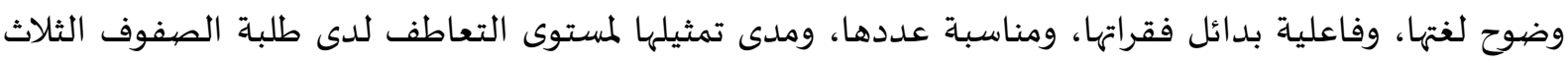

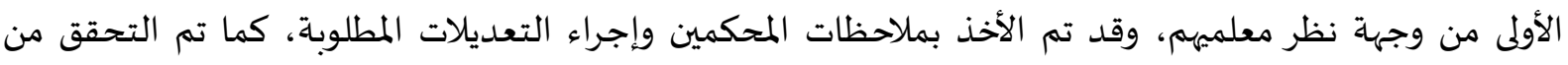
صدق الأداة إحصائيا من خلال حساب معاملات الارتباط بين استجابات العينة الاستطلاعية على فقرات أداة

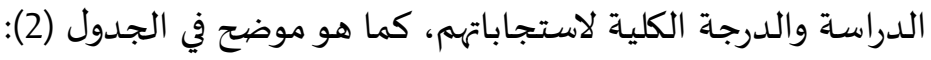


جدول (2): معاملات ارتباط فقرات أداة الدراسـة بالدرجة الكلية للمقياس:

\begin{tabular}{|c|c|c|c|c|c|c|c|}
\hline معامل الارتباط & العبارة رقم & الارتباط معامل & رقبم & معامل الارتباط & رقمبم & الارتباط معامل & العبارة \\
\hline 0.44 & 16 & 0.43 & 11 & 0.33 & 6 & 0.63 & 1 \\
\hline 0.36 & 17 & 0.55 & 12 & 0.64 & 7 & 0.42 & 2 \\
\hline 0.44 & 18 & 0.36 & 13 & 0.45 & 8 & 0.52 & 3 \\
\hline 0.36 & 19 & 0.40 & 14 & 0.52 & 9 & 0.77 & 4 \\
\hline 0.39 & 20 & 0.63 & 15 & 0.49 & 10 & 0.40 & 5 \\
\hline
\end{tabular}

يلاحظ من الجدول (2) أن معاملات ارتباط فقرات أداة الدراسة بالدرجة الكلية للمقياس قد تراوحت بين

(0.33- 0.77) وهي قيم مقبولة لغايات الدراسـة الحالية.

ثبات أداة الدراسة:

تم التحقق من ثبات أداة الدراسة من خلال التجزئة النصفية، حيث تم تطبيقها على العينة الاستطلاعية المكوّنة من (30) معلمًا ومعلمة، ومن ثم تم حساب (معامل التجزئة النصفية جتمان) على أداة الدراسة ككل وعلى ادلى

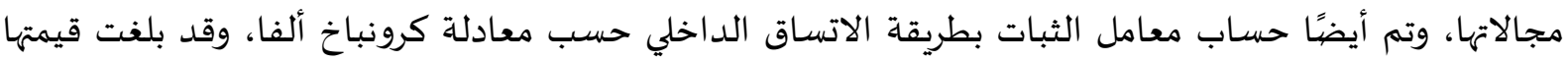
(0.77) وفي حين بلغت قيم الثبات بطريقة الاتساق الداخلي (0.84) وقد اعتبرت هذه القيم مقبولة لغايات الدراسة

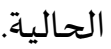

\section{مفتاح تصحيح أداة الدراسة:}

في ضوء سلم الإجابة على فقرات أداة الدراسة، وبما أن تدريج سلم الاستجابة خماسي تتراوح الإجابة على ألى

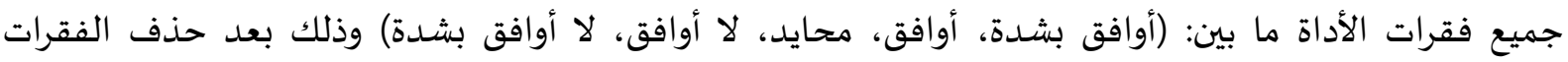

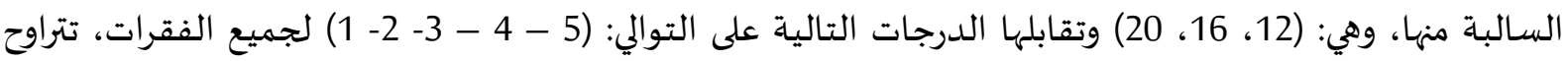

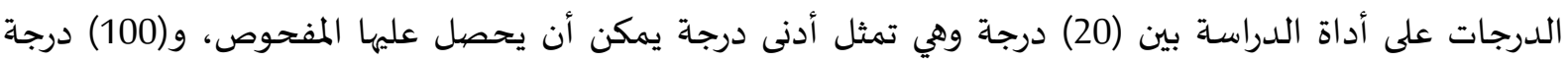

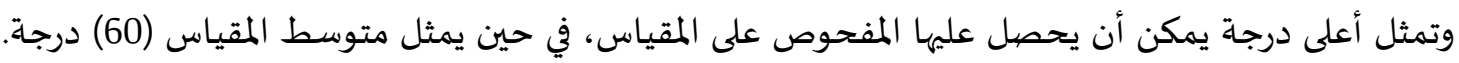

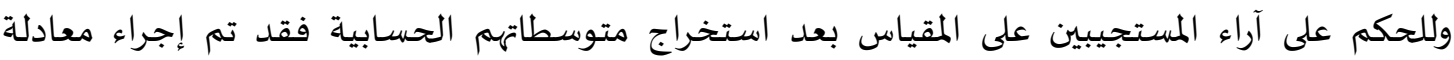

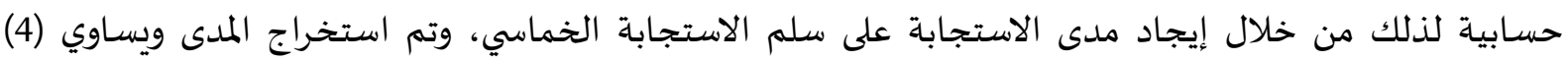

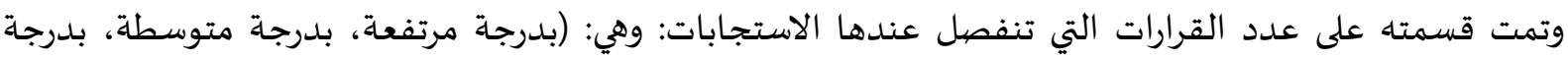

منخفضة) ثم الحكم على القيمة الناتجة، وقد كانت نقاط الحكم (نقطة القطع) (1.33)- وهي المعيار- كما يلي: جدول (3): المدى المعدل لمقياس الدراسة:

\begin{tabular}{|c|c|c|}
\hline المدى المعدل الذي يتبعه & المعيار & 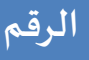 \\
\hline$(3.67-5.00)$ & درجة مرتفعة & 1 \\
\hline$(2.34-3.66)$ & درجة متوسطة & 2 \\
\hline$(1.00-2.33)$ & درجة منخفضية & 3 \\
\hline
\end{tabular}


المعالجة الإحصيائية:

تم إدخال النتائج إلى برنامج الرزم الإحصائية (Spss V.23) ثم حساب المتوسطات الحسابية والانحرافات المعيارية لدرجات أفراد عينة الدراسة على أداة الدراسة؛ وذلك لإيجاد تقصي مستوى التعاطف لدى طلبة الصفوف الثلاث الأولى من وجهة نظر معلميهم في لواء ماركا في ضوء بعض المتغيرات، ولفحص الفروق التي تعزى للمؤهل العلمي للمعلم ولخبرته فقد تم استخدام اختبار تحليل التباين الأحادي.

$$
\text { إجراءات الدراسة: }
$$

تم استخدام الإجراءات التالية بالاعتماد على أساليب البحث العلمي في تطبيق الدراسة، وهي: 1. الرجوع إلى الأدب النظري والدراسات السابقة والاستفادة من آراء المتخصصين والباحثين.

$$
\text { 2. إعداد أداة الدراسة بالشكل النهائي. }
$$

3. التحقق من الخصائص السيكومترية لأداة الدراسـة من حيث الصدق والثبات من خلال تطبيقها على عينة

$$
\text { استطلاعية مكونة من (30) معلمًا ومعلمة. }
$$

4. توزيع أداة الدراسة على عينة الدراسـة المكونة من (293) معلمًا ومعلمة من معلمي الصفوف الثلاث الأولى في

$$
\text { مديرية تربية لواء ماركا. }
$$

5. تحوي استجابات عينة الدراسة إلى درجات خام، وإدخالها إلى الحاسوب عن طريق برنامج الرزمة الإحصائية

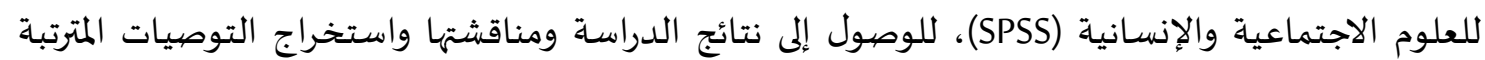
على هذه النتائج.

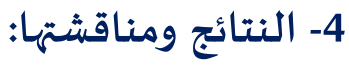
إجابة السؤال الأول: ما مستوى التعاطف لدى طلبة الصفوف الثلاث الأولى من وجهة نظر معلميهم في

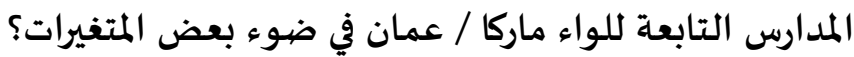

\begin{tabular}{|c|c|c|c|c|c|}
\hline 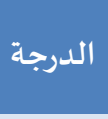 & 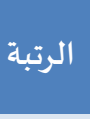 & الانمحاف & المتوسط الحسابي & 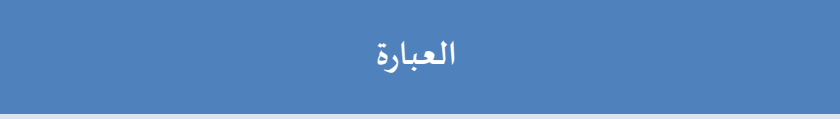 & p \\
\hline 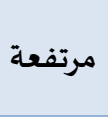 & 1 & 0.58 & 4.21 & يندفعُ الطلبة للعمل عندما يسمعون حديثًا إيجابيًا من زملائهم عن العمل. & 10 \\
\hline 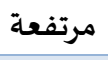 & 2 & 0.63 & 4.15 & يشعر الطلبة بالرهبة في المواقف الطارئة. & 13 \\
\hline 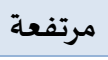 & 3 & 0.68 & 4.15 & يشعرُ الطلبة بالخوف عندما يتكلم أصداقاؤهم عن المواقف المرعبة. & 17 \\
\hline 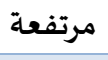 & 4 & 0.61 & 4.08 & يبادرُ الطلبة بمسـاعدة الآخرين عندما يحتاجون ذلك. & 7 \\
\hline 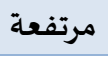 & 5 & 0.66 & 4.05 & تتأثرُ مشـاعر الطلبة بإحسـاس من حولهم بالغضب. & 15 \\
\hline 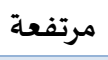 & 6 & 0.70 & 4.02 & يرى الطلبة بأنهم أشخاص يملكون قلوبًا طيبة. & 4 \\
\hline 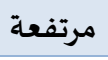 & 7 & 0.66 & 4.00 & يفقدُ الطلبة السيطرة على مشاعرهم في المواقف الضـاغطة. & 16 \\
\hline 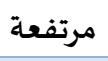 & 8 & 0.70 & 3.96 & يشعرُ الطلبة مع أصدقائهم عندما يتحدثون عن أحزانهم. & 6 \\
\hline 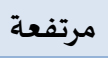 & 9 & 0.62 & 3.94 & يشعرُ الطلبة مع الآخرين عندما تواجههم المشكلات. & 2 \\
\hline 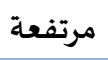 & 10 & 0.79 & 3.88 & يدركُ الطلبة مشـاعر زملائهم عندما يتحدثون عنها. & 1 \\
\hline
\end{tabular}
ولإجابة عن هذا السؤال، تم استخراج المتوسطات الحسابية والانحرافات المعيارية لاستجابات ألمات أفراد عينة الدراسة لفقرات مقياس التعاطف وعلى الدرجة الكلية للمقياس، كما يوضح في الجدول (4):

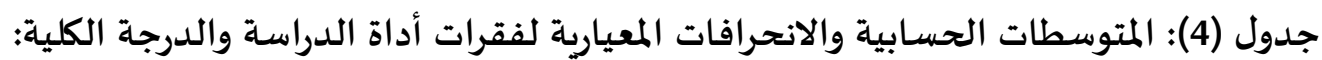




\begin{tabular}{|c|c|c|c|c|c|}
\hline 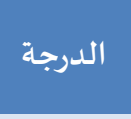 & 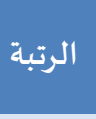 & الاندراف & المتوسط الحسابي & 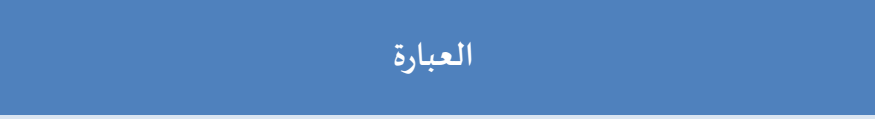 & $\hat{\imath}$ \\
\hline 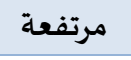 & 11 & 0.84 & 3.88 & يفهم الطلبة غضب بعضهم البعض من نبرة صوتهم. & 5 \\
\hline 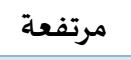 & 12 & 0.77 & 3.87 & يجد الطلبة صعوبة في إدراك ما يفكر به الآخرين حول مواقف الحياة. & 14 \\
\hline 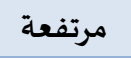 & 13 & 0.78 & 3.73 & يفهم الطلبة وجهات نظر أصدقائهم عندما يستمعون لبعضهم البعض. & 3 \\
\hline 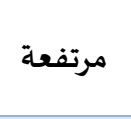 & 14 & 0.75 & 3.70 & عندما يتحدث الطلبة لزملاههم عن شعورهم بالحزن يسهلُ عليهم فهم & 9 \\
\hline متوسطة & 15 & 0.86 & 3.46 & 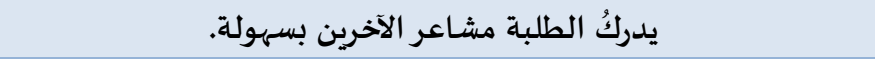 & 8 \\
\hline متوسطة & 16 & 1.02 & 3.32 & تَحْدُثُث الآخَرينَ عن مُشككلاتههم لا يُزعجُ الطَّلبة. & 19 \\
\hline متوسطة & 17 & 0.99 & 3.19 & من الصعب أن يعرفَ الطلبة متى يكون أصهدقائهم خائفين. & 12 \\
\hline متوسطة & 18 & 0.99 & 3.02 & يجدُ الطلبة صعوبة في معرفة متى يكون أصيدقاؤهم سعداء. & 18 \\
\hline متوسطة & 19 & 0.95 & 3.00 & يشعرُ الطلبة بأن مشاعر الآخرين لا تزعجهم أبدًا. & 11 \\
\hline متوسطة & 20 & 1.02 & 2.82 & لا يجيد الطلبة فهم مشاعر الآخرين. & 20 \\
\hline 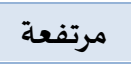 & & 0.31 & 3.72 & الدرجة الكلية لأداة الدراسة & \\
\hline
\end{tabular}

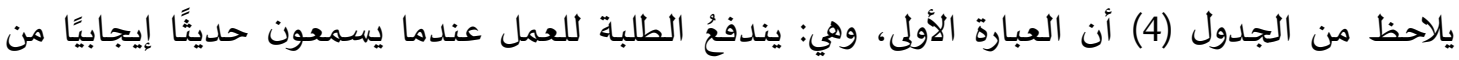

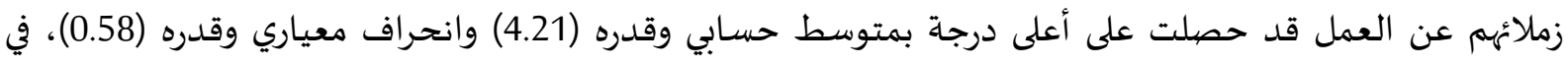

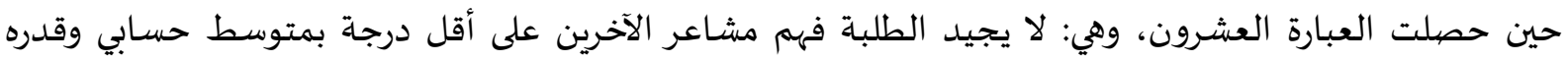

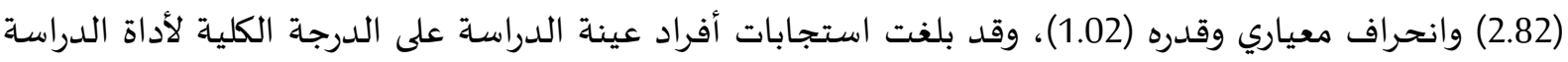

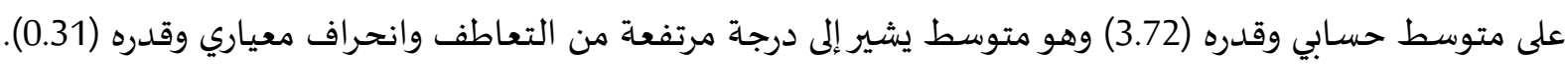

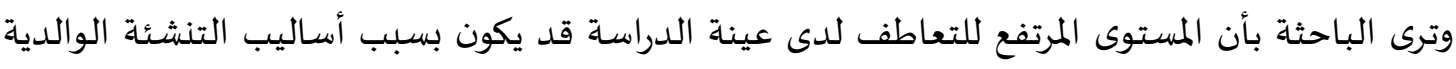
الإيجابية والقائمة على التقبل، والدفء، والتسامح، والتواد، والتراحم، حيث تزان تزرع هذه النماذجة الإيجابية وتُجذّر

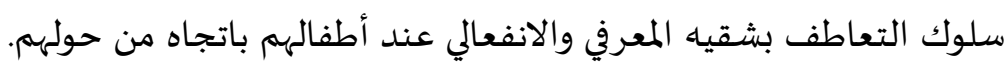

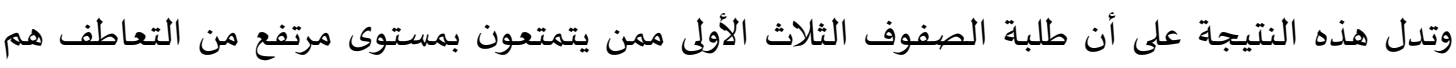

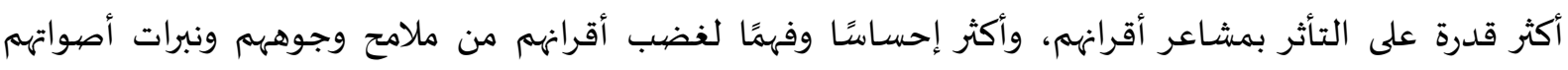

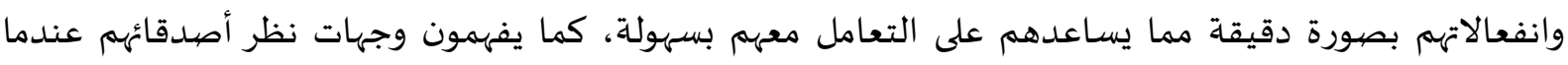

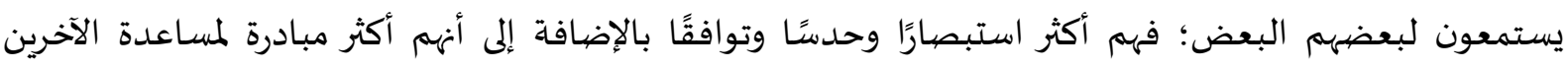

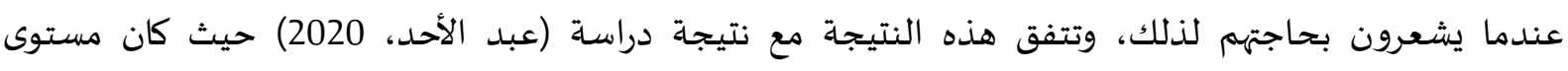

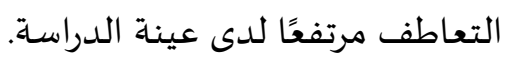

إجابة السؤال الثاني: "هل توجد فروق ذات دلالة إحصائية عند مستوى دلالة (0.05 0 (ب) في مستوى

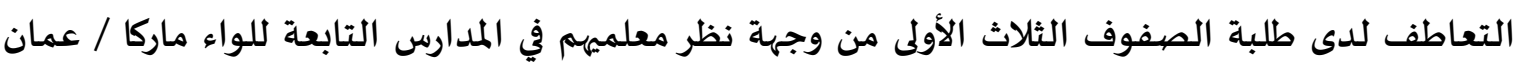

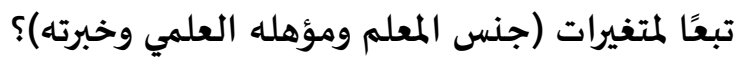

1- - 1 - فحص الفروق التي تعزى لمتغير الجنس: ولفحص الفروق التي تعزى لمتغير الجنس فقد تم حساب المتئ المتوسطات الحسابية والانحرافات المعيارية

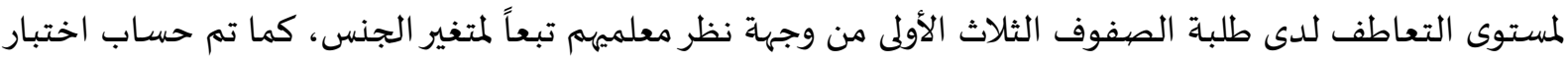
(ت) للعينات المستقلة لبيان ذلك، والجدول (5) يوضح ذلك. 
جدول (5): المتوسطات الحسابية والانحرافات المعيارية لمستوى التعاطف لدى طلبة الصفوف الثلاث الأولى تبعاً ملتغير جنس المعلم

\begin{tabular}{|c|c|c|c|c|c|c|}
\hline ذكورة & ذالفئلة \\
\hline
\end{tabular}

تشير النتائج الواردة في الجدول (5) إلى عدم وجود فروق ذات دلالة إحصائية في مستوى التعاطف لدى

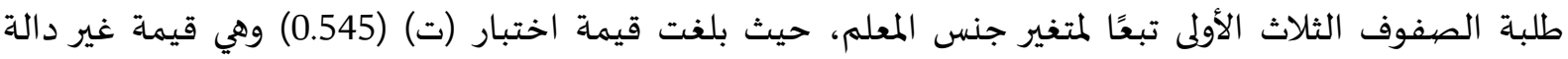

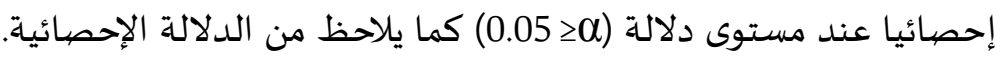

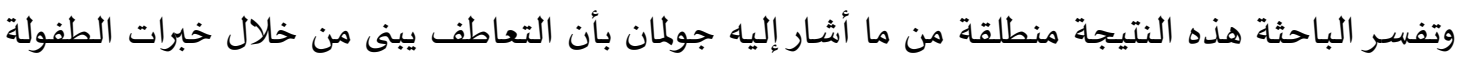

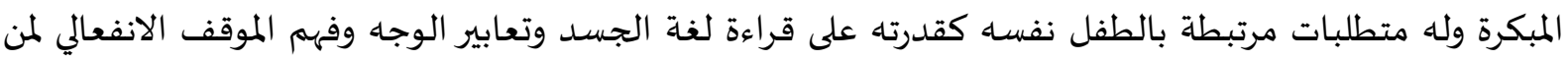

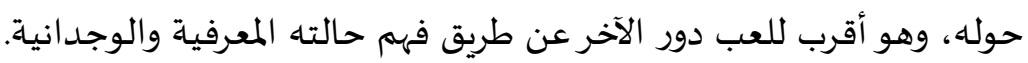

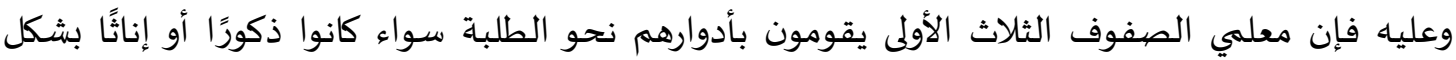

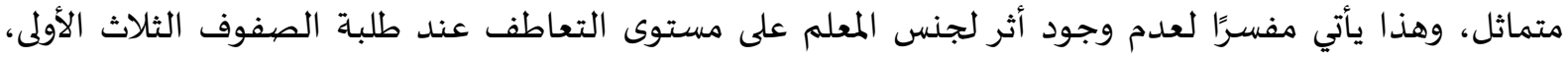

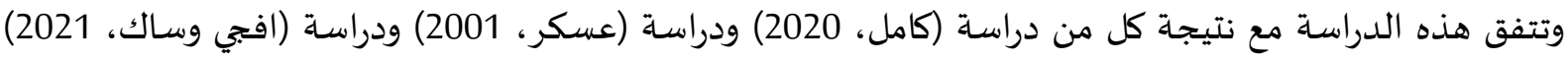
والتي تشير لعدم وجود تأثير للجنس على مستوى التعاطف لدى عيد عينة الدراسة.

\section{2- فحص الفروق التي تعزى لمتغير المؤهل العلمي} ولفحص الفروق التي تعزى لمتغير المؤهل العلمي بفئاته فقد تم حساب المتوسطات الحسابية والانحرافات

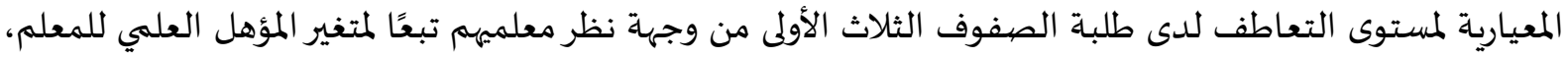
والجدول (6) يوضح ذلك. جدول (6): المتوسطات الحسابية والانحرافات المعيارية لمستوى التعاطف لدى طلبة الصفوف الثلاث الأولى تبعًا

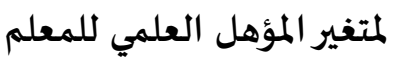

\begin{tabular}{|c|c|c|c|}
\hline 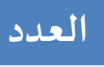 & الانحراف المعياري & المتوسط الحسابي & الفئة \\
\hline 17 & .37426 & 3.7912 & دبلوم متوسط \\
\hline 233 & .31944 & 3.7197 & بكالوريوس \\
\hline 25 & .24346 & 3.7140 & دبلوم عال \\
\hline 18 & .24846 & 3.6944 & ماجستير فأعلى \\
\hline 293 & .31233 & 3.7218 & المجموع \\
\hline
\end{tabular}

يلاحظ من الجدول (6) وجود فروق ظاهرية في مستوى التعاطف لدى طلبة الصيفوف الثلاث الأولى تبعًا لمتغير المؤهل العلمي للمعلم ولحساب الفروق الإحصائية على الدرجة الكلية لأداة الدراسة تم إجراء الحتول الدتبار تحليل

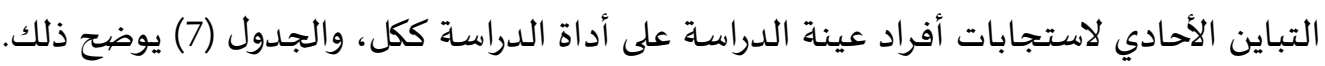


جدول (7): نتائج اختبار تحليل التباين الأحادي لحساب الفروق على الدرجة الكلية لأداة الدراسة تبعًا لمتغير المعاب المؤهل العلمي للمعلم.

\begin{tabular}{|c|c|c|c|c|c|}
\hline الإحصائية الدلاية & قيمة اختبار & متوسطات & الحرجات & مجموع المربعات & المصدر \\
\hline \multirow[t]{3}{*}{.800} & .3320 & .033 & 3 & .098 & المؤهل العلمي \\
\hline & & .098 & 289 & 28.387 & الخطأ \\
\hline & & & 292 & 28.485 & الكلي المصحح \\
\hline
\end{tabular}

تشير نتائج الجدول (7) إلى عدم وجود فروق ذات دلالة إحصائية عند مستوى دلالة (0.05

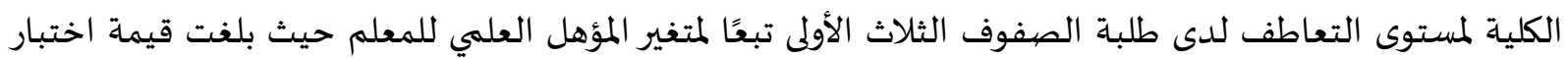
ف (0.332) وهي قيمة غير دالة إحصائية كما يظهر من الدلالة الإحصائية.

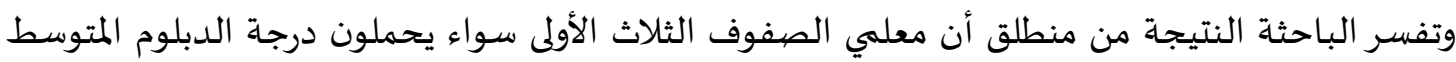

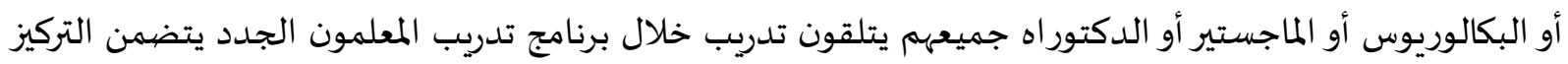

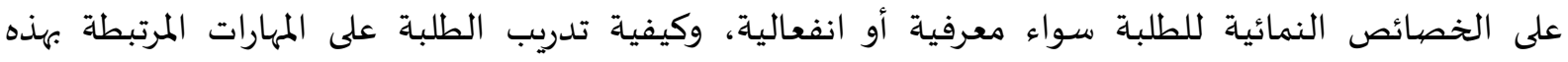

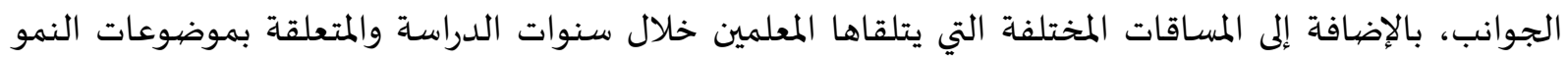

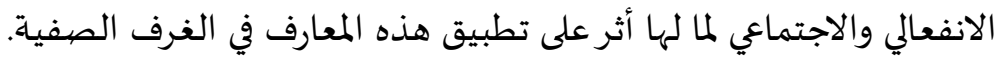

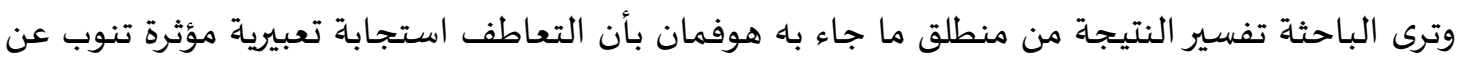

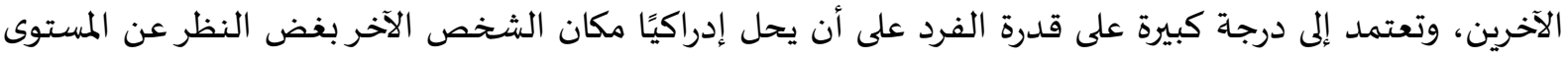

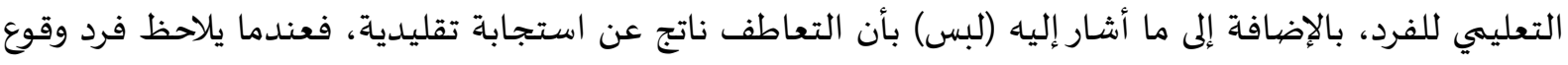

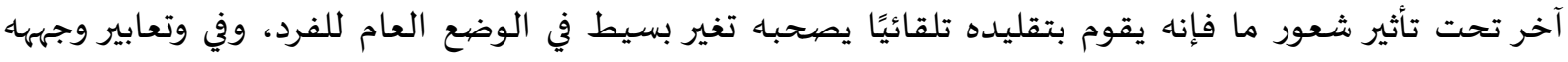

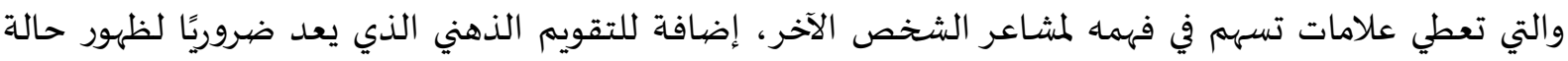

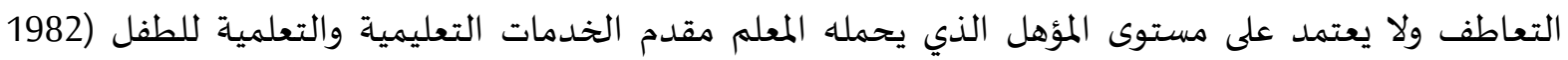

.(Hoffman,

3- فحص الفروق التي تعزى لمتغير خبرة المعلم: ولفحص الفروق التي تعزى لمتغير خبرة المعلم بفئاتها فقد تم حساب المتوسطات الحسابية والانحرافات

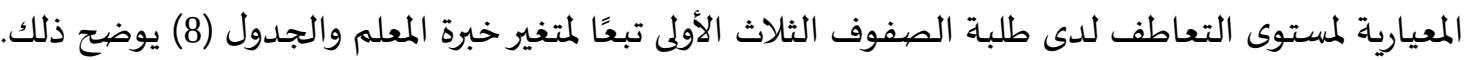

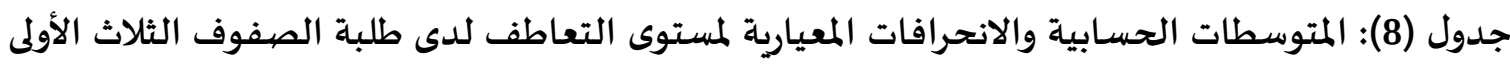
تبعًا لمتغير خبرة المعلم.

\begin{tabular}{|c|c|c|c|}
\hline العدد & الانحراف المعياري & المتوسط الحسابي & الفئة \\
\hline 67 & .34816 & 3.7701 & 1 - 5 سنوات \\
\hline 74 & .30814 & 3.7243 & 6 - 10 سنوات \\
\hline 86 & .29935 & 3.7058 & 11 - 15 سنة \\
\hline 66 & .29599 & 3.6909 & أكثر من 15 سنة \\
\hline 293 & .31233 & 3.7218 & المجموع \\
\hline
\end{tabular}


يلاحظ من الجدول (8) وجود فروق ظاهرية في مستوى التعاطف لدى طلبة الصفوف الثلاث الأولى تبعًا لمتغير خبرة المعلم ولحساب الفروق الإحصائية على الدرجة الكلية لأداة الدراسة. وتم إجراء اختبار تحليل التباين

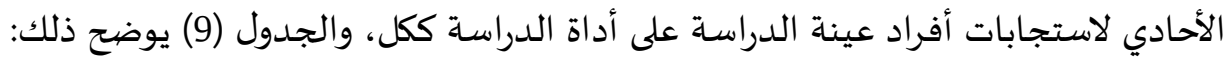
جدول (9): نتائج تحليل التباين الأحادي لحساب الفروق على الدرجة الكلية لأداة الدراسة تبعًا لمتغير خبرة

\begin{tabular}{|c|c|c|c|c|c|}
\hline & & & المعلم. & & \\
\hline الإحصلائية & قيمة اختبار & متوسطات المربعات & درجات الحرية & مجموع المربعات & المهلدر \\
\hline 0.48 & 0.826 & .081 & 3 & .242 & خبرة المعلم \\
\hline & & .098 & 289 & 28.243 & الخطأ \\
\hline & & & 292 & 28.485 & الكلي المصحح \\
\hline
\end{tabular}

تشير نتائج الجدول (9) إلى عدم وجود فروق ذات دلالة إحصائية عند مستوى دلالة (0.05 $\alpha$ إلم) في الدرجة

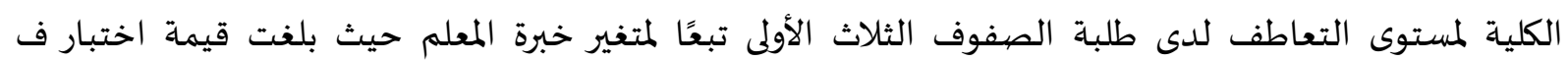
(0.826) وهي قيمة غير دالة إحصائية كما يظهر من الدلالة الإحصائية.

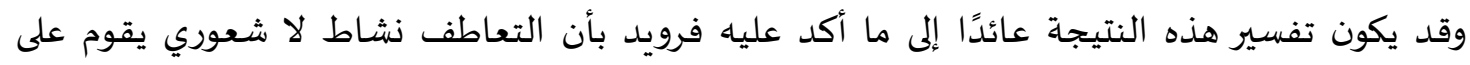

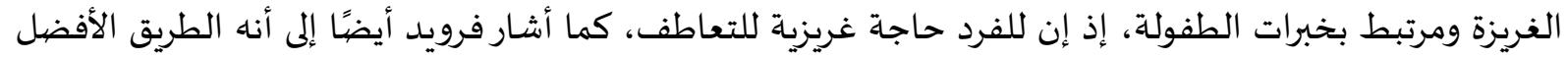

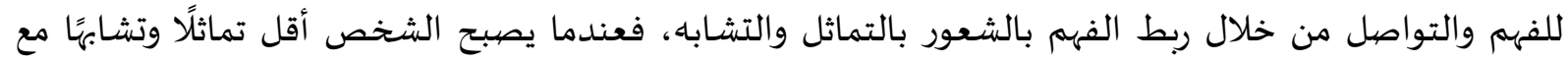

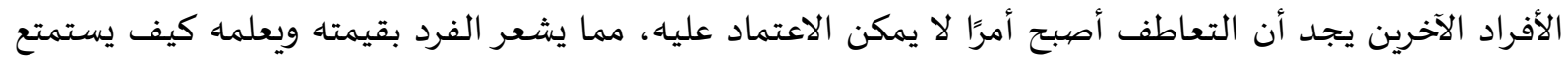

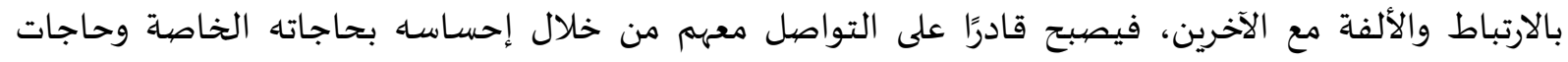
الآخرين (Scotland, 1969).

\section{مقترحات الدراسـة وتوصياتها.} 1- - تصميم برامج تدربيية لمعلمي الصفوف الثلاث وتفعيل دورهم في تنمية المهارات الانفعالية والاجتماعية لدى طلبتهم. 2- العمل على إجراء جلسات حوارية توعوية لأولياء الأمور والمعلمين فيما يخص النمو الانفعالي والاجتماعي للأطفال في الصفوف الثلاث الأولى وما قبل المدرسة. 3- عمل بحث تجريبي يركز على تنمية التعاطف لدى الطلب المبلة المراهقين ورياض الأطفال.

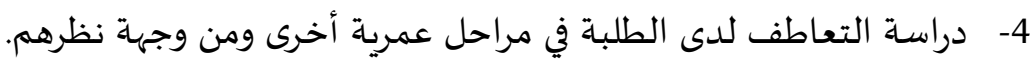

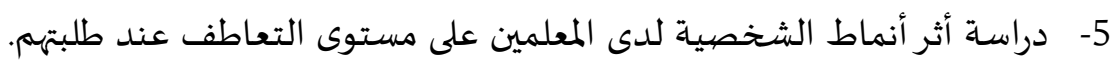
- محمد كامل"، هشام (2020). التعاطف والامتنان كمحددات للإيثار لدى عينة من الطلاب المتفوقين دراسيًا.

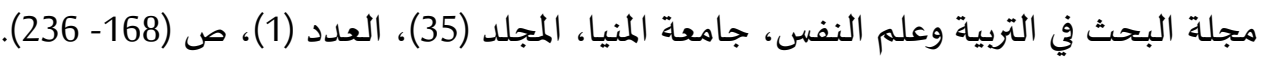


بشير، خلود (2020). الذكاء الثقافي وعلاقته بالتعاطف الوجداني لدى طلبة المرحلة الإعدادية وأقرانهم النازحين.

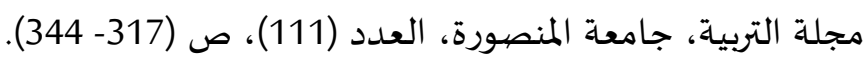

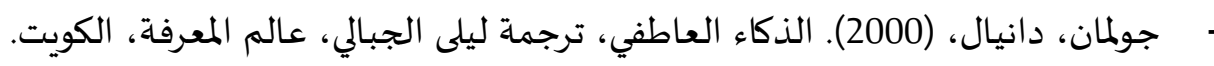

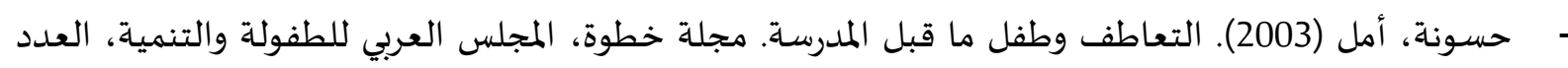

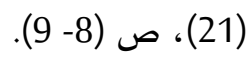

- عثمان، محمد سعد (2015). تنمية التعاطف لدى الأطفال العاديين وأثره على اتجاهاتهم نحو أقرانهم من ذوي

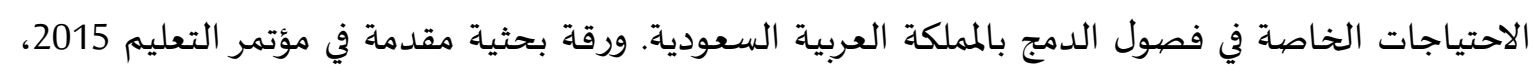

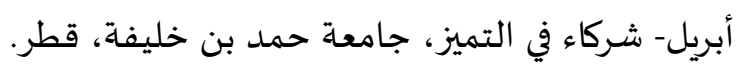

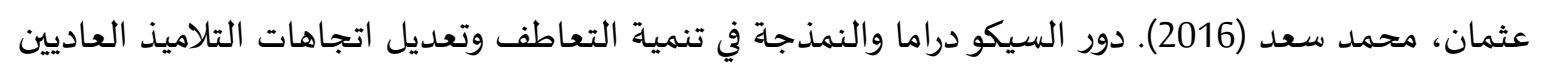

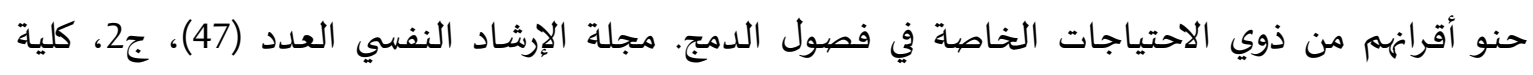
التربية، جامعة عين شمس، القاهرة.

- عسكر، سهيلة (2001). التعاطف لدى طلبة الجامعة وعلاقته بالذكاء الاجتماعي. رسالة ماجستير غير منشورة، كلية الآداب- جامعة بغداد، العراق.

- النهان، موسى (2004). مقياس الذكاء العاطفي لدى طلبة وزارة التربية والتعليم والشباب في دولة الإمارات العربية المتحدة، رسالة ماجستير غير منشورة، جامعة الإمارات العربية المتحدة.

\section{ثانياً- المراجع بالإنجليزية: - م}

- Allport G. (1960). The nature of prejudice garden city. N.Y.

- Ançel, G. (2006). Developing empathy in nurses: An inservice training program. Archives of psychiatric nursing, 20 (6), 249- 257

- Avcl, E., \& Sak, R. (2021). The relationship between parenting styles and fourth graders' levels of empathy and aggressiveness. Current Psychology, 40 (2), 510- 522.

- Bowlby, J. (1979). The making and breaking of affection bonds. New York Basic Books.

- Depew, D. (2005). Empathy, Psychology, and Aesthetics. An Interdisciplinary, Journal of Rhetorical Analysis and Invention, 4, (1), 99- 107.

- Dymond, R. (1949). A scale for the measurement of empathic ability. Journal of consulting psychology, vol.13.

- Eysenck, M.W. (2003). Key topics in A2 psychology. New York: Francis Group.

- Fredrick, S, Jenkins, L., \& Ray, K. (2020). Dimensions of empathy and bystander intervention in bullying in elementary school. Journal of School Psychology, 79, 31-42.

- Goleman, D. (1998). Working with Emotional Intelligence. Copyright, First Published in Great Britain.

- Gordon, G.)2013 (. Cognitive and Affective Empathy as Predictors of Proactive and Reactive Aggression. Unpublished Doctoral Dissertation, Duquesn University.

- Grant, A (2010). Alittle Thanks Goes along Ways:Explaining why Gratitude Expressions Motivate Prosocial. 
- Hoffman, M (1982). The measurement of empathy, In C.Izard (ed) Measuring emotions in infants and children, Cambridge:, Cambridge University press.

- Hoffman, M. (1977). Sex differences in empathy and related behavior. behaviors. Psychological bulletin, $84(4), 712$.

- Kazdin, A, E (2000). Encyclopedia of Psychology, APA, Oxford University, vol 7, p:528.

- Reid, L.M. (2003). Validation of the self- empathy scale. MA. Thesis University of Regina.

- Sctotland, E, E (1969): Exploratory studies in empathy..Berkowitz, Adv, Advanced in Experimental Social Psychology, Vol.4, New York:Academic Press.

- Thomas, R, (1979). Comparing theories of child development.wadsowrth. publishing company INC California

- Turner, j (2014). The Psychology of Emotions, USA. Cambridge University press.

- Vaknin, S (2009).Empathy and Personality. Journal of Psychology and mental health community.Wadsowrth publishing company INC. California. 